Das Leistungsverhältnis in Förderungs- und Hilfesystemen 


\title{
Die Entwicklung der „social assistance“ in Deutschland, Frankreich und im Vereinigten Königreich - von den ,armen Armen“ zu den „berechtigten Armen“
}

\author{
Karl-Jürgen Bieback
}

I. Vorbemerkung: Gegenstand der Untersuchung und Methode 218

II. „Social assistance“ als eigenständiger Leistungstyp 219

1. Allgemeine Abgrenzung $\quad 219$

a) Deutschland $\quad 219$

b) Frankreich 220

c) UK 220

2. Abgrenzung im koordinierenden europäischen Sozialrecht 221

3. Wesentliches Kriterium: Bedürftigkeit (,means-test“) 222

a) Internationales Sozialrecht und vergleichende Untersuchungen 222

b) Zwei Arten von Bedürftigkeitsbezug 222

III. Von der universellen zur speziellen „social assistance“ 223

1. Faktoren der Entwicklung 224

2. Neue Bedarfslagen und Ausdifferenzierung von Sondersystemen 226

3. Sondersysteme für Arbeitslose oder Erwerbstätige 226

a) UK: Sondersysteme für alle Erwerbstätigen und Arbeitslosen -
Dreiteilung des Systems

b) Frankreich: Mindestsicherung in den klassischen Systemen und
allgemeines System für Erwerbsfähige

c) Deutschland: Umfassendes Sondersystem für alle Erwerbsfähigen 232

d) Übersicht und zusammenfassende Bewertung 233

IV. Veränderungen in der Grundstruktur 236

1. Personeller Geltungsbereich: Migranten von außerhalb der EU 236

2. Personeller Geltungsbereich: Messung der Erwerbsfähigkeit 237

a) Wachsende Bedeutung der Leistungen an Behinderte/Erwerbsunfähige 237

b) Funktionale Vielfalt der Kriterien zur Bestimmung einer Behinderung/
Erwerbsunfähigkeit

c) Abgrenzungskriterien $\quad 239$

$\begin{array}{ll}\text { (1) UK } & 239\end{array}$

(2) Deutschland 241

(3) Frankreich 241

(4) Fazit 242

3. Personeller Geltungsbereich: Messung der Arbeitsmarktbeteiligung
bei Leistungen an Niedrigverdiener

4. Selbständiger Arbeitsmarktbürger und Bedarfsgemeinschaft 244 
a) Individueller Anspruch/Familienanspruch 244

b) Feststellung des Bedarfs - Individuen oder Bedarfsgemeinschaft 245

5. Rückgriff auf Unterhaltsansprüche - eingeschränkte Subsidiarität 246

6. Aufstockende Leistungen an Erwerbstätige: Von der Sicherung gegen
Armut zur Sicherung eines angemessenen Einkommens

a) Armutsfallen und „moral hazard“" 248

b) Ein wichtiger Entwicklungsfaktor in allen drei Ländern 249

c) Weitere sozialpolitische Aspekte 251

d) Zusammenfassung $\quad 252$

V. Besondere rechtliche Strukturen der workfare 253

1. Elemente der „workfare“ 253

2. Die Universalisierung des Erwerbstätigenstatus 254

3. Verpflichtung zur Reintegration in den Arbeitsmarkt 255

4. Vertragliche Strukturen 255

5. Sanktionen $\quad 257$

6. Einbezug in die Förderleistungen 258

7. Die Ausweitung: Von der workfare zur Inklusion 259

VI. Allgemeine sozialrechtliche und sozialpolitische Einordnung des Wandels 260

1. Zusammenfassung 260

2. Wandel im Gerechtigkeitsparadigma 261

\section{Vorbemerkung: Gegenstand der Untersuchung und Methode}

Die Aufgabe, rechtsvergleichend und in Bezug auf die Entwicklungsperspektive zu dem „Leistungsverhältnis in Förderungs- und Hilfesystemen“ zu referieren, setzt einen gemeinsamen Bezugspunkt voraus, der, das hat Zacher ${ }^{1}$ mehrfach betont, vor allem das soziale Problem, wie auch ein Systemelement und die Rechtstechnik der Problemlösung sein können. Was aber ist der systematische Ort und was sind die gemeinsamen sozialen Probleme des mir aufgetragenen Gegenstandsbereichs „Hilfe- und Förderleistungen“?

Ein gemeinsamer systematischer Bezug für das, was Hilfe- und Fördersysteme sind, lässt sich im englischen und französischen Recht, die ich hier rechtsvergleichend heranziehen werde, nicht finden. Es wird sich zeigen, dass beide Sozialrechtsordnungen ihre Leistungssysteme stärker problembezogen strukturieren. Dennoch soll versucht werden, einen (von eventuell mehreren) gemeinsamen Kernen herauszuarbeiten. Um es vorweg zu nehmen: Die bedürftigkeitsgeprüfte, subsidiäre und existenzsichernde Leistung, vor allem die Geldleistung.

Wegen der Schwierigkeiten eines gemeinsamen begrifflichen und systematischen Bezugspunkts soll zusätzlich der zweite Ansatz der rechtsvergleichenden Herangehensweise und zweite Vorschlag der Aufgabenstellung aufgegriffen und ein inhaltliches

1 Hans F. Zacher, Vorfragen zu den Methoden des Sozialrechtsvergleichs, in: ders. (Hrsg.), Methodische Probleme des Sozialrechtsvergleichs, Berlin 1977, S. 21 ff., 39 ff. 
Problem gewählt werden, das schon lange in der sozialpolitischen Diskussion länderübergreifend und vergleichend behandelt wird und das sowohl Aspekte von Hilfewie von Fördersystemen verbindet: Die Absicherung von Erwerbsfähigen, speziell Dauerarbeitslosen, durch bedürftigkeitsgeprüfte, existenzsichernde, subsidiäre Leistungen. Für den deutschen Leser kann auch das Erkenntnisinteresse befriedigt werden, wie andere Länder jene Probleme bearbeiten, die Deutschland mit dem SGB II neu strukturiert hat und bearbeiten will.

Dieses Sachproblem wird sozialpolitisch-vergleichend oft unter dem Aspekt eines Wandels von „Welfare zu Workfare“ behandelt. Gerade weil es sich dabei um eine von internationalen Akteuren, vor allem der $\mathrm{OECD}^{2}$ und der $\mathrm{EU}^{3}$, vorangetriebene Politik handelt, lassen sich an ihr in vergleichender sozialrechtlicher Hinsicht Gemeinsamkeiten wie auch Pfad- und Systemabhängigkeiten zeigen. Dadurch ist auch die ,vertikale“ Dimension des Sozialrechtsvergleichs notwendig, deren Bedeutung Zacher früh hervorgehoben hat. ${ }^{4}$

\section{II. „,Social assistance“ als eigenständiger Leistungstyp}

\section{Allgemeine Abgrenzung}

\section{a) Deutschland}

In Deutschland hat für die Klärung der Binnenstruktur des Sozialrechts die Unterscheidung von Zacher ${ }^{5}$ zwischen Vorsorge-, Entschädigungs- sowie Hilfs- und Förderungssystemen in der Wissenschaft weitgehend Anerkennung gefunden. ${ }^{6} \mathrm{Ihr}$ Vorteil gerade für unsere Untersuchung ist es, dass sie

(1) ohne Bindung an eine konkrete Sozialrechtsordnung rein nach Funktionen unterscheidet, also für eine Rechtsvergleichung gut brauchbar ist, und dass sie

(2) die zahlreichen Förderleistungen systematisch besser verortet. Mit der „social assistance" haben die Förderleistungen gemeinsam, dass die Leistungen keine kalkulier-

2 OECD, The Future of Social Protection, Paris 1988.

3 Dazu Constanze Abig, Die Europäische Beschäftigungsstrategie im Lichte des Förderns und Forderns, Sozialer Fortschritt 2005, S. $113 \mathrm{ff}$.

4 Hans F. Zacher, Horizontaler und vertikaler Sozialrechtsvergleich, in: ders. (Hrsg.), Sozialrechtsvergleich im Bezugsrahmen internationalen und supranationalen Rechts, Berlin 1978, S. 9 ff.

5 Hans F. Zacher, Einführung in das Sozialrecht der Bundesrepublik Deutschland, Heidelberg 1983, S. 20 ff; ders., Grundtypen des Sozialrechts, in: Walter Fürst (Hrsg.), Festschrift für Wolfgang Zeidler, Berlin 1987, S. $572 \mathrm{ff}$.

6 Vgl. Gerhard Igl/Felix Welti, Sozialrecht, 8. Aufl. Neuwied 2007, S. 6/7; Raimund Waltermann, Sozialrecht, 7. Aufl. Heidelberg 2008, § 5, I, 2 Rdnr. 64 ff.; Maximilian Fuchs/Ulrich Preis, Sozialversicherungsrecht, Köln 2005, § 5, II S. 36 ff. 
baren Risiken voraussetzen. Zugleich macht die Gruppenbildung deutlich, dass auch die „social assistance“ fördernde Elemente hat, dass es nicht nur um Existenzsicherung, sondern um soziokulturelle Teilhabe und Chancengleichheit geht.

Das materielle Sozialrecht dagegen basiert nicht auf einer solchen Unterscheidung, sondern zählt in $\S \S 18-29$ SGB I nur die einzelnen Zweige nach den wesentlichen Gesetzen auf, die sich sehr grob nach den gesicherten Risiken und Bedarfen unterscheiden.

\section{b) Frankreich}

Zwar wird die Kompetenznorm für die Soziale Sicherheit in Art. 34 der Verfassung von 1958 weit interpretiert („les principes fondamentaux de la sécurité sociale“). ${ }^{7}$ Aber das einfache materielle Recht definiert die Regime der Sozialen Sicherheit rein enumerativ nach bestimmten, meist versicherungsmäßigen Leistungen, in die auch die durchweg bedürftigkeitsabhängige Sicherung des Existenzminimums integriert ist, ${ }^{8}$ und schließt nicht die dem Arbeitsrecht zugeordnete Arbeitslosenversicherung wie auch nicht die „aide sociale“9 ein. ${ }^{10}$ Nur die französische Sozialrechtswissenschaft hebt den kategorieellen Unterschied hervor zwischen den allgemeinen Regimen der Sozialen Sicherheit einerseits und der ,,aide sociale“ mit ihren besonderen Merkmalen der Bedürftigkeit, Subsidiarität und Universalität andererseits. ${ }^{11}$

\section{c) $U K$}

Anders als Frankreich und wie Deutschland kannte und kennt das UK mit ,income support“12 eine Leistung, die in Funktion und Struktur der deutschen ,social assistance“ recht nahe kommt. Eine differenziertere Systematik findet sich in der Literatur und der offiziellen Statistik des UK insoweit, als die Sozialleistungen in drei Gruppen geteilt werden: Leistungen auf der Basis von Beiträgen, Leistungen nach Bedürftigkeit („means-test") und Leistungen, die nicht durch Beiträge, sondern aus Steuern finanziert

7 Michel Borgetto/Robert Lafore, Droit de l'aide et de l'action sociales, 6. Aufl. Paris 2006, S. 60/61, Rdnr. 72.

8 Die sog. minima sociaux. Zu ihnen unten Fußn. 41 und 42.

9 Sie ist geregelt im code de l'action sociale et de familles art. $111 \mathrm{ff}$.

10 Code de la sécurité sociale art. L111-1 und R111-1.

11 So die Teilung des Stoffes zwischen den beiden Lehrbüchern Borgetto/Lafore, Droit de l'aide et de l'action sociales (Fußn. 7) und Michel Borgetto/Robert Lafore/Rolande Ruellan, Droit de la sécurité sociale, 15. Aufl. Paris 2005. Zur innersystematischen Bedeutung des Prinzips der Subsidiarität: Maryse Badel, Subsidiarité et aide sociale: quelle actualité, Revue de Droit Sanitaire et Social (RDSS) 2007, S. 1077.

12 Social Security Contributions and Benefits Act 1992, sect. 124 ff. und Income Support Regulations 1987 SI 1987/1967. Zur Entwicklung Nicholas Wikeley, The Law of Social Security, 5. Aufl. London 2002, S. $272 \mathrm{ff}$. 
werden, aber keine Bedürftigkeit voraussetzen. ${ }^{13} \mathrm{Da}$ aber zunehmend mehr und gerade die hier interessierenden Leistungen an erwerbsfähige Arbeitslose und an Behinderte als Sozialversicherungsleistungen wie als bedürftigkeitsbezogene Leistungen bis auf die Bedürftigkeitsprüfung völlig gleich ausgestaltet sind (s. unten III, 3, a), handelt es sich letztlich nur noch um ein Kriterium von sehr geringer Relevanz. Bedeutsam ist eher noch die Unterscheidung nach den Zwecken/Zielen und den gesicherten Risiken und Bedarfen. ${ }^{14}$

\section{Abgrenzung im koordinierenden europäischen Sozialrecht}

Das internationale und europäische Sozialrecht folgen dagegen einer sehr viel schlichteren Zweiteilung. Die ILO-Abkommen 102 und 118 definieren ihren sachlichen Anwendungsbereich katalogmäßig durch die Aufzählung bestimmter Zweige der sozialen Sicherung (u. a. Leistungen bei Arbeitslosigkeit und Familienleistungen). Diesem Konzept folgt auch das europäische koordinierende Sozialrecht (Art. 4 VO (EWG) 1408/71), das aber ausdrücklich in Art. 4 Abs. 4 die „social assistance“ („,'assistance sociale“; „social assistance“) von seinem sachlichen Geltungsbereich ausnimmt. Gleichlautend, aber ohne Abgrenzung zu den anderen Leistungssystemen lässt es Art. 24 Abs. 2 RL 2004/38/EG zu, dass EU-Bürger in den ersten drei Monaten ihres Aufenthalts in einem anderen Mitgliedstaat von Leistungen der "social assistance“ („'’assistance sociale“; „,social assistance“) ausgeschlossen werden können.

„Sozialhilfe“ wird im Koordinationsrecht der EU definiert 15

- einmal durch das im Sozialrecht der Mitgliedstaaten längst überholte Unterscheidungskriterium, dass auf „social assistance“ Leistungen kein fester Anspruch bestünde, sie vielmehr nach Ermessen gewährt würden,

- zum anderen aber durch die Ausrichtung auf eine spezielle Bedarfslage/ein spezielles Risiko (dann Soziale Sicherheit) bzw. die Befriedigung allgemeiner Bedarfe (dann ,social assistance“) und

- schließlich danach, dass die Leistungen der „Sozialhilfe“ nur bei Bedürftigkeit und subsidiär gewährt werden.

Auch die VO (EG) 883/04 ändert an diesem wenig klaren dichotomischen Schema nichts. ${ }^{16}$ Dieser Zweiteilung soll nicht gefolgt werden, da sie zu wenig differenziert ist und längst überholte Kriterien tradiert.

13 Wikeley, The Law of Social Security (Fußn. 12), S. 18 ff.; implizit: David Bonner et al., Social Security legislation 2007, Vol. I, Non Means Tested Benefits, Ammanford 2007; Neville Harris, The Shape and Characteristics of Social Security Today, in: ders. (Hrsg.), Social Security Law in Context, Oxford 2000, S. $158 \mathrm{ff}$.

In der offiziellen Statistik: http://www.dwp.gov.uk/asd/asd4/Table1.xls.

14 Harris, The Shape and Characteristics of Social Security Today (Fußn. 13), S. 155 ff., 156 ff. und $162 \mathrm{ff}$.

15 Vgl. Fuchs/Preis, Sozialversicherungsrecht (Fußn. 6). 


\section{Wesentliches Kriterium: Bedürftigkeit (,,means-test“)}

\section{a) Internationales Sozialrecht und vergleichende Untersuchungen}

Was bleibt als allgemeines Unterscheidungskriterium der drei nationalen Sozialrechtsordnungen zur Kennzeichnung dessen, was man „social assistance - Recht“ nennen könnte? Es sind vor allem der „Bedürftigkeitsbezug“ und damit auch die Subsidiarität, sowie - nicht durchgängig, aber überwiegend - die Funktion der Existenzsicherung, die eine wichtige Rolle spielen.

Sie haben auch in der Charta der Grundrechte und anderen Instrumenten des europäischen und internationalen Sozialrechts eine zentrale Bedeutung. Denn Art. 34 Abs. 3 der Grundrechtecharta der EU von 2000 bestimmt „social assistance“ inhaltlich nach zwei Kriterien: (1) das Ziel ein menschenwürdiges Dasein zu sichern (existenzielles Minimum) (2) für jene Personen, die nicht über ausreichende eigene Mittel verfügen (Bedürftigkeit). Auch in den beiden wichtigsten einschlägigen Abkommen des Europarats findet sich eine ähnliche Definition: Die Bestimmung der „Fürsorge“ im Europäischen Fürsorgeabkommen v. 11.12.1953 (Art. 2) ${ }^{17}$ und in Art. 12 / 13 ESC. Diese Kriterien entwickelte auch die große vergleichende sozialpolitische Untersuchung zur ,social assistance" von Tony Eardley u.a. 1996. 18

Im Folgenden soll dieser Begrifflichkeit gefolgt werden. Um eine Verwechslung mit dem aktuellen Sprachgebrauch in einer der drei untersuchten Rechtsordnungen zu vermeiden, wird hier der im internationalen Recht geläufige, aber in keiner der drei Rechtsordnung verwandte Begriff „social assistance“ für alle bedürftigkeitsbezogenen (Geld-) Leistungen benutzt.

\section{b) Zwei Arten von Bedürftigkeitsbezug}

Dabei ist Bedürftigkeitsbezug noch zu differenzieren:

- Er kann sich einmal auf das Existenzminimum beziehen, stockt also die vorhandenen Ressourcen nur bis zu einer festen Grenze auf, will also Armut vermeiden, oder

16 Art. 3 VO (EG) 883/04 ist weitgehend identisch mit Art. 4 VO (EWG) 1408/71.

17 „Personen ohne ausreichende Mittel, die Mittel für ihren Lebensbedarf sowie die Betreuung erhalten, die ihre Lage erfordert".

18 Tony Eardley et al., Social Assistance in OECD-Countries, Synthesis Report, Department of Social Security, Research Paper No. 47, London 1996, S. 26 und ff. Zu Recht kritischer in Bezug auf Frankreich Jean Claude Barbier/Bruno Théret, Welfare-to-Work or Work-to-Welfare: The French Case, in: Neil Gilbert/Rebecca A. Van Voorhis (Hrsg.), Activating the Unemployed, New Brunswick/London 2001, S. 135. 
- er beschränkt sich auf eine Einkommensabhängigkeit, will also allenfalls vermeiden, dass die Gutsituierten die Leistungen beanspruchen. 19

Es ist ein Ergebnis dieser Analyse, dass auch bei existenzsichernden, bedürftigkeitsgeprüften Leistungssystemen die Einkommensabhängigkeit an Bedeutung gewonnen hat (unten IV.6.).

Weiterhin nicht ausreichend dogmatisch erfasst sind die Förderleistungen. Dies wird auch die Analyse zeigen: Die Förderleistungen zur Arbeitsmarktintegration werden völlig frei, rein nach Gesichtspunkten der Effektivität ausgestaltet; sie folgen keinen festen Strukturen und geben den Bürgern so gut wie keine kalkulierbare soziale Sicherheit. Da sich zudem ein anderer Block unserer Tagung mit den Familienleistungen befasst, werde ich diesen Aspekt nicht vertiefen.

\section{Von der universellen zur speziellen ,, social assistance“}

Mit den großen Reformen der Sozialen Sicherheit nach dem 2. Weltkrieg und der damit verbundenen Neukonzipierung des Basissystems der Fürsorge gingen der sozialpolitische Mainstream und der Gesetzgeber im UK, ${ }^{20}$ in Frankreich ${ }^{21}$ und Deutschland 22 mit der Schaffung der Sozialversicherungssysteme davon aus, dass das allgemeine Fürsorgesystem nur noch eine marginale Rolle spielen würde, da die Sozialversicherung und die Familienleistungen (Kindergeld/child benefit) die meisten Armutssituationen (Alter, Kinderreichtum, Invalidität) verhindern bzw. eigenständig absichern würden. Es ist Konsens in allen drei Ländern, dass die Entwicklung der Empfängerzahlen und die ständige Ausdifferenzierung und Erweiterung der „social assistance“ zeigen, dass das Gegenteil eintrat. ${ }^{23}$

19 Es geht dann um „poverty testing“ einerseits und „means“ oder ,income testing“ andererseits vgl. Ian Gough et al., Social Assistance in OECD Countries, Journal of European Social Policy 1997, S. 19.

20 William Beveridge, Social Insurance and Allied Services, London 1942, Cmd (Parlamentsdrucksache) 6404, Nr. 369; Wikeley, The Law of Social Security (Fußn. 12), S. 269/270.

21 Borgetto/Lafore, Droit de l'aide et de l'action sociales (Fußn. 7), S. 22 ff., Rdnr. 26 ff. und S. 70/71, 77 ff. Rdnr. 80 ff., 86 ff.

22 Vgl. die Begründung zum BSHG BT-Drs. 3/1799, 33/34; Dieter Giese, Die Entwicklung des BSHG seit 1962, in: Johannes Münder (Hrsg.), Zukunft der Sozialhilfe, Münster 1988, S. 9 ff.

23 Allg. Eardley et al., Social Assistance in OECD-Countries (Fußn. 18), S. 36 ff.; UK: Wikeley (Fußn. 20); Frankreich: Borgetto/Lafore (Fußn. 21); Deutschland: Giese (Fußn. 22). 


\section{Faktoren der Entwicklung}

Die Gründe, für die zunehmende Bedeutung der „social assistance“ können am Beispiel der Leistungen an Erwerbsfähige und speziell an Arbeitslose gut aufgezeigt werden. In allen drei Ländern ähnelten sich die gesellschaftlichen Rahmenbedingungen, während die „Pfadabhängigkeit“ erst bei den Lösungen wirkte und das Ergebnis, die Zunahme von Leistungen der „social assistance“ bei der Sicherung gegen Arbeitslosigkeit wiederum gleich war.

a) Das stagnierende Wirtschaftswachstum und der Anstieg der Arbeitslosigkeit, speziell der Langzeitarbeitslosigkeit, führten zu einem (relativen) Rückgang der Beiträge zur Sozialversicherung und bei gleichzeitigen Steuersenkungen zu (relativ) abnehmenden Staatsausgaben für die Systeme der Sozialen Sicherheit.

Dies veranlasste alle drei Länder die Leistungen der Sozialen Sicherheit in den „Hauptsystemen“ der Sozialversicherung zu senken, ${ }^{24}$ wodurch das letzte Sicherheitsnetz, die ,social assistance“ wieder an Bedeutung gewann. Am radikalsten war der Umbau im UK wo die einkommensabhängigen Leistungen von $1991 \mathrm{zu}$ 2006/7 erheblich stärker wuchsen als die nicht einkommensabhängigen. ${ }^{25}$ Für das UK und Deutschland, ${ }^{26}$ ebenfalls für Frankreich ${ }^{27}$, dort aber weniger ausgeprägt, lassen sich z. B. allgemein und speziell bei der Arbeitslosenversicherung 28 zwei Phasen unterscheiden: (1) Bei Beibehaltung der klassischen Institutionen und Systeme zuerst die Kürzung von Dauer und Höhe der Sozialleistungen und die Beschränkung des Zugangs zu ihnen plus strengere Anforderungen an die Risikovermeidung und Sanktionen für die Risikoherbeiführung. (2) Überleitung der Sicherungsfunktion auf rein bedürftigkeitsbezogene Leis-

24 Revue française des affaires sociales (Ministère des affaires sociales), 1/2006, Réformes de la protection sociale en Europe; Paul Pierson, Coping with Permanent Austerity: Welfare State Restructuring in Affluent Democracies, in: ders. (Hrsg.), The New Politics of the Welfare State, Oxford, 2001, S. 410-456; Peter Taylor-Gooby (Hrsg.), Welfare States Under Pressure, London 2002. Für Deutschland und UK Jens Borchert, Die konservative Transformation des Wohlfahrtsstaates, Frankfurt a.M. 1995 und Jochen Clasen, Reforming European Welfare States: Germany and the United Kingdom Compared, Oxford 2005 sowie Peter Starke, Radical Welfare State Retrenchment, A Comparative Analysis, London (Palgrave) 2007, S. 155 ff.

251991 machten die nicht einkommensabhängigen Leistungen das 2,8-fache der einkommensabhängigen Leistungen aus, 2006/7 dagegen nur noch das 2,2-fache, vgl. die Statistiken unter http://www.dwp.gov.uk/asd/asd4/Table1.xls.

26 Kathrin Mohr, Soziale Exklusion und Wohlfahrtsstaat, Arbeitslosenversicherung und Sozialhilfe in Großbritannien und Deutschland, Wiesbaden 2007; dies., Wandel der Arbeitsmarktpolitik in Großbritannien und Deutschland, Zeitschrift für Sozialreform, Wiesbaden 2008, S. 187.

27 Mit dem nationalen berufsübergreifenden Abkommen über die Modernisierung des Arbeitsmarkts v. 21.1.2008, das seit Ende April 2008 im Gesetzgebungsverfahren ist, erfolgt eine Reform der Sozialversicherung, die noch einmal die Sanktionen bei Verweigerung eines geeigneten Stellenangebots verschärft.

28 Mohr, Soziale Exklusion und Wohlfahrtsstaat (Fußn. 26). 
tungen und dadurch der Wechsel von einem System der Statussicherung zu einem System der reinen Existenzsicherung.

b) Begünstigt wird dies dadurch, dass die Arbeitslosenversicherung stärker als die sonstige Sozialversicherung das Risiko in Umfang und Dauer immer nur beschränkt sicherte und durch bedürftigkeitsgeprüfte Sondersysteme und/oder die allgemeine „social assistance" ergänzt wurde. ${ }^{29}$

c) Es wächst der Niedriglohnbereich und mit ihm die Notwendigkeit, Niedrigeinkommen durch „social assistance“ aufzustocken. ${ }^{30}$ Eine Ursache dafür war die Flexibilisierung der Arbeit (Teilzeit- und geringfügige Arbeit) und eine im UK starke, in Deutschland mittlere und in Frankreich eher geringe Deregulierung des Arbeitsmarkts. ${ }^{31}$

d) Doppelte Leistungs- und Finanzierungszuständigkeit: Die Systeme zur Sicherung vor Arbeitslosigkeit, Sozialversicherung und „social assistance“ wurden und werden in Deutschland und Frankreich unterschiedlich finanziert und von unterschiedlichen Behörden administriert, was zu Überschneidungen und Widersprüchen und partiellen Überlastungen führen musste.

e) Kosteneinsparung erhofften sich alle Regierungen mit dem Übergang auf das „,billigste“ System, der „social assistance“ für Arbeitslose.

f) Systemspezifische Ursachen: Die finanzielle Belastung der Kommunen war in Deutschland ein ganz wichtiger Auslöser der Reform der Absicherung der Arbeitslosen durch die „social assistance“. In Frankreich waren die „minima sociaux“ der Sozialversicherung und die Familienleistungen nicht ausreichend für die Absicherung der dauerhaft Erwerbslosen und führten zur Einführung einer allgemeinen Grundsicherung, dem RMI.

29 Karl-Jürgen Bieback, Die Reform der Arbeitsförderung (SGB III und II) - eine Zwischenbilanz, SGb 2005, S. 481.

30 Eve Caroli/Jerome Gautie (Hrsg.), Low-wage work in France, New York 2008; Gerhard Bosch/Claudia Weinkopf (Hrsg.), Low-wage work in Germany, New York 2008; Caroline Lloyd/Geoff Mason/Ken Mayhew (Hrsg.), Low-wage work in the United Kingdom, New York 2008 (alle drei in: Russell Sage Foundation, Case studies of job quality in advanced economies). Zum Umfang dieses Phänomens vgl. die diskrepanten Einschätzungen in DIW Wochenbericht 4/2008 S. 33 (eher gering) und Wilhelm Adamy, Staat subventioniert Armutslöhne mit Milliardenbeträgen, Soziale Sicherheit, 6/7 2008, S. 219 (umfangreich und wachsend).

31 Dazu Christine Erhel/Hélène Zajdela, The dynamics of social and labour market policies in France and the United Kingdom, Journal of European Social Policy 14 (2004), S. 125 ff., zu einem allg. Vergleich der Deregulierung und Niedriglohnpolitik. 


\section{Neue Bedarfslagen und Ausdifferenzierung von Sondersystemen}

Diese Faktoren schlagen sich vor allem darin nieder, dass die „social assistance“ in viele unterschiedliche Systeme ausdifferenziert wird. Man kann sie danach unterscheiden, 32 ob sie

(1) allgemein, gar universell sind und im Wesentlichen nur mangelndes Einkommen und Bedürftigkeit voraussetzen (die „social assistance“ alten Typs in Deutschland und im UK); bei ihnen geht es deshalb meist nur um Armutsvermeidung, also die Sicherung des Existenzminimums. Oder sie sind

(2) speziell, indem sie

- entweder nur an bestimmte Personengruppen geleistet werden (z. B. Arbeitslose; Alleinerziehende) wie die minima sociaux in Frankreich und die bedürftigkeitsgeprüfte Absicherung der Arbeitslosen in Deutschland und im UK,

- oder der Befriedigung bestimmter Bedarfe, ohne genauere Kennzeichnung der Personengruppe (z. B. des Wohnbedarfs) dienen.

Leistungen der letzten Gruppe sind meist nur einkommensabhängig, nicht aber unbedingt subsidiär zu anderen Sozialleistungen. Zu ihnen zählen vor allem auch die Förderleistungen.

Der demographische und familiale Wandel führte in allen drei Ländern zu Sondersystemen der „social assistance“ für Familien und Kindererziehung (als wichtige Untergruppe Alleinerziehende) und zur Pflege, die nur teilweise in Frankreich (Familienkassen) und Deutschland (Pflegeversicherung) als Sozialversicherungsleistungen und im UK als allgemeine Staatsbürgerleistungen (Pflege) organisiert wurden, immer aber auch als "social assistance“ Leistungen in diesen neuen Aufgabenbereichen relevant blieben. Vor allem aber zeigt sich der Wandel hin zu speziellen Systemen in den ,social assistance" Leistungen an Erwerbsfähige und ihre Reintegration in den Arbeitsmarkt.

\section{Sondersysteme für Arbeitslose oder Erwerbstätige}

a) UK: Sondersysteme für alle Erwerbstätigen und Arbeitslosen - Dreiteilung des Systems

Nach dem Krieg kannte das UK ähnlich wie das deutsche System eine klare Trennung und Systematisierung zwischen den Leistungen der Sozialversicherung nach dem

32 Vgl. die Unterscheidungen bei Eardley et al., Social Assistance in OECD-Countries (Fußn. 18), S. $27 / 28$. 
„Beveridge-“ Modell und einigen universellen, nicht beitrags- sondern steuerfinanzierten Leistungen (,"child benefit“) einerseits und ,income support“ 33 andererseits. ${ }^{34}$

Die Leistungen an Arbeitslose wurden im UK 1995/1996 in einem Leistungssystem zusammengefasst: Jobseeker's Allowance - Unterstützung für Arbeitssuchende, wobei das System zweigeteilt, aber einheitlich ist. Es wird der selbe Betrag unter ansonsten gleichen Voraussetzungen an sozialversicherte (,contribution-based“) wie an nichtsozialversicherte Personen (,income-based“) in Höhe eines Grundbetrags von 59,15 $£ /$ Woche für alle über 25 Jahre (2007/8) gezahlt. Zwar müssen sich alle Personen Arbeitseinkommen wie in der allgemeinen „social assistance“, dem ,income support“ nach einem Freibetrag von 5£/Woche und Renten nach einem Freibetrag von 50£/Woche anrechnen lassen. Aber bei den Sozialversicherten werden - im Unterschied zum ,income support" und zum bedürftigkeitsbezogenen Arbeitslosengeld - sonstiges eigenes Einkommen, das Einkommen des Lebenspartners und das Vermögen nicht berücksichtigt. Die nach Bedürftigkeit gewährte Arbeitslosenleistung ist genauso hoch wie die Versicherungsleistung, plus Zuschläge für unterhaltsberechtigte Ehepartner und Kinder. Wegen dieser Zuschläge kann die Höhe der bedürftigkeitsbezogenen Arbeitslosenleistung die der Versicherungsleistung übersteigen. Der Differenzbetrag kann nach vorangehender Bedürftigkeitsprüfung ergänzend zur Sozialversicherungsleistung gewährt werden.

Schon in den 1970er Jahren wurden aus der allgemeinen „social assistance“ Sondersysteme für Personen mit Kindern und mit zu geringem (Arbeits-) Einkommen ausgegliedert. ${ }^{35}$ Was als besondere zusätzliche Leistung zur Milderung der Armut von Familien begann, ist nunmehr ein Sondersystem für alle niedrigverdienenden Erwerbstätigen, allerdings immer noch mit einer besonderen Familienkomponente. Wer 16 Std./Woche mit einem Kind oder über 50 Jahre alt bzw. 30 Std./Woche ohne Kind erwerbstätig aber noch hilfebedürftig, also Geringverdiener ist, erhält eine speziell auf die „working poor“ zugeschnittene Leistung, den „,working tax credit“36 (bei Kindererziehung plus den ,child tax credit") mit höheren Grundbeträgen und günstigen Quoten der Anrechnung von Einkommen (nur zu 37 \% nach einem Freibetrag von jährlich 5.220 £) und hohen Vermögensfreibeträgen. Sie sind nicht nur bedürftigkeitsbezogen, sondern werden auch wie laufende Leistungen in monatlichen Raten gezahlt. ${ }^{37}$

33 Jetzt Social Security Contributions and Benefits Act 1992, sect. 124 ff. und Income Support Regulations 1987 SI 1987/1967.

34 Zur Entwicklung Wikeley, The Law of Social Security (Fußn. 12), S. 2 ff., speziell von income support S. 272 ff.

35 Über Family Income Supplement (1970) zu Family Credit (1989) zu Working Families' Tax Credit (1999) zu Working Tax Credit und Child Tax Credit (2002/3).

36 Tax Credit Act 2002. Ausführlich dazu Herbert Düll, Arbeitsanreize im Kontext des SteuerTransfer-Systems: Ein ausgewählter internationaler Vergleich, BArbBl 4/2006, S. 4, 8/9.

37 Da aber jährlich mit der Steuer abgerechnet mit großer Gefahr der Über-/Unterzahlungen, vgl. Dan Finn et al., Delivering benefits, tax credits and employment services, Joseph Rowntree Foundation, 2008, S. $21 \mathrm{ff}$. 
Auch die neue Employment and Support Allowance 38 (Oktober 2008) löst die Leistungen an Behinderte unterhalb des Rentenalters aus der allgemeinen „social assistance“ wie der Sozialversicherung heraus und gewährt, wie die Job Seekers' Allowance, einheitliche Leistungen für vorher Sozialversicherte wie auch für bedürftige nicht vorher Sozialversicherte ohne Arbeit und betont stärker als früher die Leistungen zur Integration in den Arbeitsmarkt.

Parallel zur Einführung der ,jobseeker's allowance“ wird auch die allgemeine „,social assistance“ „,income support“ ganz auf spezifische Gruppen umgestellt. Sie erhalten nur noch jene Gruppen, bei denen nach der alten Rechtsprechung keine Arbeitsbereitschaft erforderlich war, wobei sie auch über $16 \mathrm{Std}$./Woche arbeiten können; vor allem sind dies: ${ }^{39}$

- Alleinerziehende und Personen, die „hauptberuflich“ eine schwerbehinderte Person pflegen;

- Personen unter 24 Jahren in Trainingsmaßnahmen.

b) Frankreich: Mindestsicherung in den klassischen Systemen und allgemeines System für Erwerbsfähige

Frankreich hat traditionell ein hochkomplexes unübersichtliches System der „social assistance" mit im Wesentlichen folgenden Zweigen:

- die sozialen Minima, die fast alle auf das vorherige Einkommen bezogenen Sozialversicherungsleistungen bis zu einem Mindestbetrag aufstocken,

- eine allgemeine Basisleistung zur Reintegration,

- einkommensabhängige Familienleistungen und

- ein sehr komplexes System der „social assistance“ im engeren Sinne (aide sociale und action sociale).

Auch die Unterstützungen zur Versorgung mit Wohnraum sind alle einkommensabhängig und haben Sonderregelungen für Arbeitslose, sie senken z. B. die Einkommensgrenzen nach zwei Monaten der Arbeitslosigkeit. 40

38 Clause 12-14 Welfare Reform Bill 2007, Part 1; durch noch nicht entworfenen Regulation (Dept. Of Work and Pensions, Welfare Reform Bill, Draft Regulations and supporting material, 2007, S. 5960) konkretisiert durch die sehr voluminösen Employment and Support Allowance Regulations 2008 (ESA Regulations), SI 2008/794 sowie Employment and Support Allowance (Transitional Provisions) Regulations 2008 (SI 2008/795) und Employment and Support Allowance (Consequential Provisions) Regulations 2008 (SI 2008/1082). Überblick bei Simon Rahilly, Reforming Incapacity Benefit to make it fit the Welfare to Work agenda (2006) 13 Journal of Social Security Law, S. 191; David Bonner, Employment and Support Allowance: Helping the sick and disabled to return to work?, demnächst in Journal of Social Security Law 2008, London.

39 Social Security Contributions and Benefits Act 1992, s. 124 (1)(e) und Income Support Regulations Reg 4 ZA und Schedule 1B.

40 Es handelt sich um die l'allocation de logement à caractère familial (ALF), l'allocation de logement à caractère social (ALS) et l'aide personnalisée au logement (APL). Zu ihnen Borgetto/Lafore, Droit 
(1) Soziale Minima: Fast alle Systeme der Sozialversicherung (einschließlich der Arbeitslosenversicherung) haben ergänzende/aufstockende Leistungen der Mindestsicherung (les revenus minimaux garantis) ${ }^{41}$, die aus Steuermitteln, z. T. auch aus Beitragsmitteln finanziert werden und fast durchweg bedürftigkeitsabhängig42 und subsidiär sind; sie werden jedoch durchgängig von den jeweiligen Trägern der Sozialversicherung mitverwaltet. Sie sind volumenmäßig der weitaus größte Teil der „social assistance“ Leistungen. ${ }^{43}$ Neben solchen für Rentner, Hinterbliebene etc. sind dies:

- Für Arbeitslose, die in den letzten 10 Jahren vor ihrer Arbeitslosigkeit mindestens 5 Jahre abhängig beschäftigt waren und deren Leistungen aus der Arbeitslosenversicherung ausgelaufen sind, die l'allocation de solidarité spécifique (ASS) von 1984. ${ }^{44}$ Die Leistungen betragen für einen Erwachsenen $442 €$, bei langer Vorversicherungszeit oder hohem Alter (55/57) und längerer Vorbeschäftigung (20/10 Jahre) $634 €$ im Monat. ${ }^{45}$ Sie setzt Arbeitsfähigkeit und Verfügbarkeit für die Arbeitsvermittlung voraus. ${ }^{46}$ Sie ist zentralstaatlich geregelt, wird über einen Fonds finanziert und zugeteilt, die Arbeitsbereitschaft und die Integrationsmaßnahmen werden von der lokalen/regionalen Arbeitsmarktverwaltung geprüft und administriert ${ }^{47}$; nur die hoheitlichen Entscheidungen der Streichung von der Liste der Arbeitssuchenden und die Verhängung der Sanktionen trifft der Präfekt des Departments. ${ }^{48}$ Zuschläge für Kinder, besondere Bedarfe etc. gibt es nicht; sie werden von den Familienkassen über besondere, bedarfsabhängige Familienleistungen getragen (sogleich). Für Arbeitslose gibt es also wie früher in Deutschland ein „duales System“ mit der Versicherungsleistung 49 (ca. $75 \%$ des vorherigen Lohns bis maximal 36 Monate) und der besonderen „social assistance“ für Arbeitslose.

de l'aide et de l'action sociales (Fußn. 7), S. 603 ff.; zu den neueren Änderungen und dem Umfang Fußn. 43, S. 7.

41 Übersicht bei Jean-Jacques Dupeyroux, Droit de la sécurité sociale, 15. Aufl. Paris 2005, S. 346 ff.; Borgetto/Lafore, Droit de l'aide et de l'action sociales (Fußn. 7), S. 525 ff., Nr. 564 ff.

42 Es sind vor allem Leistungen an Behinderte: La prestation de compensation des personnes handicapées, Borgetto/Lafore, Droit de l'aide et de l'action sociales (Fußn. 7), S. 409 ff., Nr. 414 ff. und einige Familienleistungen Dupeyroux, Droit de la sécurité sociale (Fußn. 41), S. 348, 728 ff., die man wegen ihres besonderen Zwecks kaum zu den klassischen Leistungen der „social assistance“ zählen kann. Vgl. auch Barbier/Théret (Fußn. 18), S. 142 ff.

43 Hierzu und zu den folgenden quantitativen Aussagen: Direction de la recherche, des études, de l'évaluation et des statistique (DREES), Études et Résultat n 604 - octobre 2007, Les prestations de protection sociale en 2006 unter http://www.travail-solidarite.gouv.fr/etudes-recherche-statistiquesdrees/publications/etudes-resultats/.

44 Artikel L5423-1ff. des Arbeitsgesetzbuchs (Code du travail n.F.).

45 Art. 4 Décret $n^{\circ}$ 2008-52 du 16 janvier 2008, JORF nº014 du 17 janvier 2008.

46 Code du travail Article L5421-1 und $3 \mathrm{ff}$.

47 Code du travail L5426-1 und L5426-2 und R5426-1 bis 14.

48 Code du travail R5426-1 bis 14.

49 Code du travail Artikel L5422-1 bis L5422-21 plus Abkommen der Sozialpartner vom 18. Januar 2006. 
- Für ältere Arbeitslose mit langer Vorversicherungszeit (40 Jahre) wird bis $2009^{50}$ über eine besondere bedürftigkeitsgeprüfte Leistung mit Beträgen oberhalb der AAS und höheren Freibeträgen für das Einkommen die l'allocation équivalent retraite (AER) bis zum Bezug einer Altersrente gezahlt. 51

- Für Behinderte die Beihilfe für behinderte Erwachsene (allocation aux adultes handicapés, AAH von 1975), 52 für Personen im Alter von 20 bis 60 Jahren, die zumindest zu $80 \%$ auf Dauer behindert sind oder aufgrund einer Behinderung zwischen $50-80 \%$ als arbeitsunfähig anerkannt sind und deren Einkünfte unter dem gewährten Betrag (599,49 €/Monat) liegen. In den Leistungen und der Anrechnung ist sie die großzügigste. ${ }^{53}$

(2) Allgemeine Basisleistung: Während alle besonderen, die Sozialversicherung aufstockenden, ergänzenden oder ablösenden ,social assistance“ Leistungen teilweise bis zu den Reformen nach dem 2. Weltkrieg zurück reichen, ${ }^{54}$ ist das neue „Auffangsystem" für Personen, die keinen Anspruch auf eine Sozialversicherungsleistung oder ein sie ergänzendes soziales Minimum haben, die allgemeine Fürsorgeleistung zur Integration (revenu minimum d'insertion, RMI), ${ }^{55}$ das 1988 als Antwort auf die Krise des Arbeitsmarktes und der Sozialversicherung geschaffen wurde. ${ }^{56}$ Es wird nur an über 25jährige gewährt und setzt nur voraus, dass eine Person bedürftig und zu Maßnahmen der sozialen Eingliederung bereit ist. In dieser sehr allgemeinen Konzeption und der zwingenden Verbindung mit einer Integrationsmaßnahme ist das RMI als eine große sozialpolitische Neuheit angesehen worden. ${ }^{57}$ Die Unterhaltsleistung beträgt für einen einzelnen Erwachsenen $2008447 €$ (Paar $671 €$ ) monatlich, ${ }^{58}$ mit Zuschlägen für Familienangehörige, Kinder, Wohnungskosten.

(3) Einkommensabhängige Familienleistungen/Leistungen zur Aufstockung: Neben der „social assistance“, die die allgemeinen Systeme der Sozialversicherung ergänzt, und dem RMI klafft eine Lücke für Leistungen an Niedrigverdiener. Diese Funktion übernimmt einmal z. T. auch das traditionell weit verzweigte System der Familienleistungen, darunter die ständig gewachsenen ,prestations familiales sous conditions de res-

50 Abgeschafft durch article 132 de la loi de finances pour 2008 (JORF n 300, 27 décembre 2007, S. 21211).

51 Code du travail article L5423-1.

52 Code de la sécurité sociale, art. L. 821-1 et s., R. 821-1 et s. et D. 821-1 et s.

53 Hierzu und zur Reform: Serge Milano, Parechever la réforme de l'AHH, RDSS 2008, S. 148 ff.

54 Zur Geschichte Borgetto/Lafore, Droit de l'aide et de l'action sociales (Fußn. 7), S. 18 ff.; Dupeyroux, Droit de la sécurité sociale (Fußn. 41), S. 349 ff., Rdnr. 463 ff.

55 Sozial- und Familiengesetz (Code de l'action sociale et de la famille), Artikel L 262-1 ff.

$56 \mathrm{Zu}$ seiner sozialpolitischen Einschätzung: Otto Kaufmann, Revenu minimum d'insertion in Frankreich. Wegweiser für neue Formen der sozialen Sicherheit?, ZfSH/SGB 1990, S. 394.

57 Herman Deleeck/Bea Cantillon, Le minimum garanti, Droit social 1986, S. 479 ff.; Chantal Euzeby, Le revenu minimum garanti. Expériences et propositions, Revue international du travail 1987, S. 281.

58 Art. 1 Décret n 2008-52 du 16 janvier 2008, JORF nº014 du 17 janvier 2008. 
sources“, 59 die entweder von den Familienkassen aus Beitragsmitteln geleistet werden, also Sozialversicherungsleistungen sind (an Alleinerziehende, zur Geburt und zum Schulbeginn) ${ }^{60}$ oder die z. T. von der Selbstverwaltung der Departements gezahlt werden. ${ }^{61} \mathrm{Zu}$ letzteren gehören auch Leistungen ohne festen Rechtsanspruch, die rein auf die individuellen Bedarfe ausgerichtet sind.

Neu eingeführt wurde 2001 die prime pour l'emploi (PPE), eine negative Einkommenssteuer zur Existenzsicherung. ${ }^{62}$ Sie ist voll in das Steuersystem integriert. Personen, die im Jahr mindestens 3.743 (im Monat $400 €$ ) verdient haben, also in relevantem Maße am Erwerbsleben teilnahmen, und die (2008) bis zum Höchstbetrag von 17.451 $€ / J a h r$ verdienen, erhalten zu ihrem Einkommen einen Prozentsatz (7,7 oder 19,3\%) der Differenz zum Höchstsatz; bei Teilzeitarbeit wird nur ein Teilbetrag ausgekehrt. Die Ersatzquote ist gemessen an der negativen Einkommenssteuer des UK also gering. Die relativ höchste Förderung erhält, wer Vollzeit zum Mindestlohn (SMIC) arbeitet, der maximale jährliche Betrag belief sich 2007 auf $809 € / \mathrm{Jahr}$. Es profitierten davon 2005 ca. 9,1 Millionen Haushalte bei Gesamtkosten von 2,7 Milliarden €.63

Im Erprobungsstadium befindet sich noch das Revenu de solidarité aktive (RSA) von 2007, das alle sozialen Minima zusammenfasst und die Einkommensverluste beim Übergang zur niedrig entlohnter Arbeit auf oder über den Mindestlohn, also Niedrigeinkommen aufstocken soll. ${ }^{64}$

(4) Aide sociale und action sociale sind die ebenfalls staatlichen oder gemeindlichen „social assistance“ Leistungen, sind aber umfassender angelegt und betreffen vor allem

59 Dazu: Julien Damon, La mise sous conditions de ressources des allocations familiales: une disrimination vraiment positive?, RDSS 2008, S. 336. Nur die reine ,allocation familiale“ wird erst ab dem 2. Kind geleistet; viele setzen nur das Zusammenleben mit einem Kind voraus: aide personelle au logement, allocation du soutien familial, allocation parent isolé, allocation du éducation specialisée etc. Vgl. zur Ausweitung Philippe Steck, Des allocations familiales dès le premier enfant?, Droit social 2007, S. 1278.

60 Code de la securité sociale art. 531-14.

61 Code de l'action sociale et des familles Art. 111, Art. 121-1 ff. Knappe Übersicht bei Borgetto/Lafore, Droit de l'aide et de l'action sociales (Fußn. 7), S. 271 ff., Rdnr. 296 ff. Jean-Pierre Laborde, Les Prestations familiales: pluralité des typologies, incertitude de la notion, RDSS 1994, S. 563. S. auch den alten Code de la famille et de l'aide sociale Title III, Art. $150 \mathrm{ff}$.

62 Aktueller Stand: http://www.travail-solidarite.gouv.fr/informations-pratiques/fiches-pratiques/ remuneration /prime-pour-emploi-ppe.html?var_recherche=PPE (25.4.2008).

Herbert Düll, Arbeitsanreize im Kontext des Steuer-Transfer-Systems: Ein ausgewählter internationaler Vergleich, BArbBl 4/2006, S. 4, 9/10.

63 Siehe http://www.finances.gouv.fr/presse/dossiers_de_presse/ministre/plf2007/dispo_fisc/1-2ppe.pdf.

64 Siehe das livre vert vom Februar 2008: http://www.premierministre.gouv.fr/information/ les_dossiers_actualites_19/haut_commissaire_solidarites_actives_920/experimentations_924/livre vert_sur_rsa_1281 und Inspection générale des finances $\bar{N}^{\circ}$ 2007-M-092-01, Rapport sur la mise en place du revenue de solidarité active, Decembre 2007. 
die betreuende Sozialarbeit und Hilfeleistungen für bestimmte Personengruppen. ${ }^{65}$ Wegen der speziellen ,social assistance“ Leistungen (vor allem der Spezialleistung der „aide sociale“, dem RMI) und der strikten Subsidiarität spielen sie aber nur eine geringe Rolle.

\section{c) Deutschland: Umfassendes Sondersystem für alle Erwerbsfähigen}

Deutschland hat traditionell nicht so umfassende Sozialversicherungssysteme wie England und Frankreich und garantiert innerhalb dieser Systeme keine Mindestleistungen. Deshalb musste die „social assistance“ immer einen breiten Kreis von Risiken und Personengruppen absichern und war im Ansatz allgemein und deshalb in sich auch stark individuell. Die alte „social assistance“ (BSHG) hatte neben der allgemeinen Leistung für den Lebensunterhalt auch besondere (höhere) Leistungen für spezielle Bedarfe und Personengruppen. ${ }^{66}$ Neben der alten „social assistance“ wurden noch die Familienleistungen und die Wohnförderung aus besonderen Systemen geleistet, die nicht nur für „social assistance“ Empfänger gelten.

Seit 2004 gibt es eine spezielle ,social assistance“ für Erwerbsfähige (SGB II „Grundsicherung für Arbeitssuchende"), die für diese Personengruppen auch die Familienbedarfe mit höheren Leistungen als im allgemeinen Kindergeld und die Wohnkosten mit ebenfalls höheren Leistungen als im allgemeinen Wohngeld abdeckt. Höhere Leistungen gibt es für werdende Mütter, Alleinerziehende und Behinderte sowie Personen mit besonderem medizinischen Aufwand (§ 21 SGB II). Die allgemeine Sicherung des Existenzminimums durch die „social assistance“ (SGB XII) hat damit ihre Bedeutung weitgehend verloren. Sie ist letztlich nur noch relevant als Sicherung des Existenzminimums für erwerbsunfähige Behinderte und Alte über 65 Jahren ( $\S 41$ ff. SGB XII) sowie in der Sonderform einer speziellen Leistung mit relativ hohen Einkommensgrenzen zur Rehabilitation Behinderter und zur Pflege (§§ 51-66 SGB XII). ${ }^{67}$

Im SGB II wie im SGB XII hat die Basisleistung zur Sicherung des Existenzminimums die gleiche Höhe und den gleichen Umfang; die Leistungen werden durchweg pauschaliert.

65 Code de l'action sociale et des familles Art. $111 \mathrm{ff}$. Borgetto/Lafore, Droit de l'aide et de l'action sociales (Fußn. 7), S. 87 ff.

$66 \S 23$ : werdende Mütter, Alleinerziehende, Ältere und Behinderte; § 27: Hilfe bei Krankheit, vorbeugende und sonstige Hilfe, Behinderte, Blinde, Pflege, Weiterführung des Haushalts, besondere soziale Schwierigkeiten, Alte, mit erheblich höheren Freibeträgen für das anzurechnende Einkommen.

67 Zahlen unter: http://www.destatis.de/jetspeed/portal/cms/Sites/destatis/Internet/DE/Content/ Statistiken /Sozialleistungen/Sozialhilfe/Tabellen sowie Sozialhilfestatistik 2006, Wirtschaft und Statistik 2007, S. 1245 ff. 2003 bezogen noch 2,8 Mio. Personen die allgemeine Sozialhilfe zum Lebensunterhalt, 2006 nur noch 0,3 Mio., 1,3 Mio. erhalten die großzügigere Hilfe in besonderen Lebenslagen, vor allem für Behinderte und Pflegebedürftige und 0,68 Mio. die Grundsicherung im Alter und bei Erwerbsminderung. 
Die Grundsicherung nach dem SGB II wird auch an beschäftigte Niedrigverdiener geleistet, deren Zahl in den letzten Jahren stetig gewachsen ist. 68 Ähnlich wie England und Frankreich hat auch Deutschland mit der Neuregelung 2004 dann, wenn die ,social assistance" Bedürftigkeit allein durch den Bedarf der Kinder entstehen würde, eine Aufstockung des allgemeinen Kindergeldes ( $§ 6 \mathrm{a} \mathrm{BKGG})$ eingeführt und erst kürzlich erhöht, ${ }^{69}$ um ,social assistance“ Bedürftigkeit von Personen zu vermeiden, die an sich für sich selbst über ausreichende eigene Einkünfte verfügen und nur durch die Versorgung ihrer Kinder unter die „social assistance“ Schwelle rutschen.

Sonstige relevante einkommensabhängige Leistungen gibt es nur noch beim Wohngeld und in der Förderung von Auszubildenden.

\section{d) Übersicht und zusammenfassende Bewertung}

Die folgende Übersicht arbeitet mit dem oben entwickelten Begriff der „social assistance": alle Leistungen, die unter der Bedingung der Bedürftigkeit geleistet werden. Sie konzentriert sich auf die speziellen Leistungen für Erwerbstätige. Es sind auch Leistungen aufgeführt, die in das Steuersystem integriert sind. Nicht aufgeführt sind die indirekten Leistungen an Niedrigeinkommensbezieher in Form der allgemeinen steuerlichen Freibeträge und die Freibeträge/geringeren Sätze bei den Sozialversicherungsabgaben.

68 Ihre Zahl wuchs von 287.000 im Januar 2005 auf 557.893 im November 2007: www.pub.arbeitsamt.de/hst/ser-vices/statistik.

69 Er soll ab 1.10.2008 maximal $140 €$ pro Kind betragen zusätzlich zum Kindergeld von $154 €$ und dem Wohngeld bei einem Mindesteinkommen von $600 €$ für Alleinerziehende und $900 €$ für Paare. Vgl. BT-Drs. 16/8867 sowie zur bisherigen Handhabung BT-Drs. 16/7586 v. 17.12.2007. 


\section{Übersicht über die bedürftigkeitsgeprüften Leistungen (,social assistance“)}

\begin{tabular}{|c|c|c|c|}
\hline \begin{tabular}{|l} 
Land \\
Armutsgruppe/ \\
Spez. Leistungen \\
\end{tabular} & UK & Frankreich & Deutschland \\
\hline $\begin{array}{l}\text { Erwerbstätige „wor- } \\
\text { king poor“ (durch } \\
\text { Niedriglohn, Fami- } \\
\text { lienlasten) }\end{array}$ & $\begin{array}{l}\text { Working Tax Credit ab } 16 \\
\text { Std/Woche wenn mindestens } \\
1 \text { Kind oder ab } 30 \mathrm{Std} / \text { Woche } \\
\text { oder } \\
\text { Income Support (IS) für spe- } \\
\text { zielle Gruppen } \\
\text { jeweils + Child Tax Credit + } \\
\text { Child Benefit) }\end{array}$ & $\begin{array}{l}\text { Familienleistungen (zuneh- } \\
\text { mend nach Bedürftigkeit) } \\
\text { Steuerliche Leistungen (prime } \\
\text { pour l'emploie) ab Verdienst } \\
\text { über 400€/Monat } \\
\text { Übergangszahlungen wenn } \\
\text { vorher ASS oder RMI }\end{array}$ & $\begin{array}{l}\text { Kindergeld (nicht } \\
\text { nach Bedürftigkeit) } \\
\text { und Zuschlag zum } \\
\text { Kindergeld } \\
\text { oder } \\
\text { SGB II (ohne weitere } \\
\text { Voraussetzung) }\end{array}$ \\
\hline $\begin{array}{l}\text { Arbeitslose }=\text { Er- } \\
\text { werbsfähige ohne } \\
\text { relevante Erwerbs- } \\
\text { tätigkeit }\end{array}$ & $\begin{array}{l}\text { Sofort Job Seekers' Allow- } \\
\text { ance JSA (Beschäftigung un- } \\
\text { ter } 16 \mathrm{Std} / \text { Woche) zu etwas } \\
\text { besseren Bedingungen für } \\
\text { Sozialversicherte in den ers- } \\
\text { ten } 6 \text { Monaten }\end{array}$ & $\begin{array}{l}\text { Allocation de solidarité spéci- } \\
\text { fique (ASS) nach Ende Ar- } \\
\text { beitslosenvers., wenn Vorbe- } \\
\text { schäftigungszeiten; sonst re- } \\
\text { venu minimum d'insertion } \\
\text { (RMI) }\end{array}$ & $\begin{array}{l}\text { evtl. aufstockendes } \\
\text { SGB II zur Lohner- } \\
\text { satzleistung der Ar- } \\
\text { beitslosenversiche- } \\
\text { rung, nach Auslaufen } \\
\text { der Arbeitslosenver- } \\
\text { sicherung SGB II } \\
\end{array}$ \\
\hline $\begin{array}{l}\text { (Vorübergehend) } \\
\text { nicht erwerbstätige } \\
\text { Erwerbsfähige (Al- } \\
\text { leinerziehende) }\end{array}$ & $\begin{array}{l}\text { Income Support - Aufzählung } \\
\text { bestimmter Gruppen }\end{array}$ & $\begin{array}{l}\text { Familienleistg. bei Bedürf- } \\
\text { tigkeit für bes. Belastung, Al- } \\
\text { leinerziehende, Kosten der } \\
\text { Betreuung } \\
\text { RMI } \\
\end{array}$ & $\begin{array}{l}\text { SGB II - alle über } \\
\text { Generalklausel; Zu- } \\
\text { schläge für Alleiner- } \\
\text { ziehende }\end{array}$ \\
\hline $\begin{array}{l}\text { Dauerhaft Nichter- } \\
\text { werbsfähige unter } \\
65\end{array}$ & $\begin{array}{l}\text { IS oder Incapacity Benefit; } \\
\text { Ab Okt. 08: Employment and } \\
\text { Support Allowance, Grundbe- } \\
\text { träge oberhalb IS }\end{array}$ & $\begin{array}{l}\text { Allocation aux adultes handi- } \\
\text { capés und/oder } \\
\text { revenue minimum d'insertion }\end{array}$ & $\begin{array}{l}\text { Unter } 3 \mathrm{St} / \text { Tag er- } \\
\text { werbsfähig Er- } \\
\text { werbsminderungs- } \\
\text { rente der RV + SGB } \\
\text { XII (Grundsiche- } \\
\text { rung) mit Zuschlägen } \\
\text { für Alleinerziehende } \\
\end{array}$ \\
\hline $\begin{array}{l}\text { Nicht Erwerbsfähi- } \\
\text { ge über } 65\end{array}$ & $\begin{array}{l}\text { Öff. + priv. Rente, Income } \\
\text { support }\end{array}$ & $\begin{array}{l}\text { Allocation de solidarité aux } \\
\text { personnes âgées/Allocation } \\
\text { personalisée d'autonomie } \\
\text { (Pflegehilfe) }\end{array}$ & $\begin{array}{l}\text { RV-Rente + SGB } \\
\text { XII (Grundsiche- } \\
\text { rung); Hilfe zur } \\
\text { Pflege des SGB XII } \\
\end{array}$ \\
\hline $\begin{array}{l}\text { Integrations- } \\
\text { leistungen }\end{array}$ & $\begin{array}{l}\text { Extra, nach dem allg. Niveau } \\
\text { für andere Arbeitslose, spe- } \\
\text { zielle Programme für Fürsor- } \\
\text { geempfänger }\end{array}$ & $\begin{array}{l}\text { Extra, sei es durch die Ar- } \\
\text { beitsmarktbehörde, sei es auf } \\
\text { Ebene der Departements ver- } \\
\text { waltet, vom Staat finanziert }\end{array}$ & $\begin{array}{l}\text { In SGB II und SGB } \\
\text { XII eingeschlossen, } \\
\text { weitgehend nach } \\
\text { dem allg. Muster für } \\
\text { Arbeitslose (SGB III, } \\
\text { IX) }\end{array}$ \\
\hline Kinderkosten & $\begin{array}{l}\text { Für IS und JSA: Child Benefit } \\
\text { und Child Tax Credit }\end{array}$ & $\begin{array}{l}\text { Familienleistungen (teilweise } \\
\text { nach Bedürftigkeit); die we- } \\
\text { sentlichen ab 2. Kind }\end{array}$ & $\begin{array}{l}\text { In SGB II und SGB } \\
\text { XII eingeschlossen }\end{array}$ \\
\hline Wohnungskosten & $\begin{array}{l}\text { Zusätzliche spezielle Leis- } \\
\text { tung: Housing Benefit, Local } \\
\text { Housing Allowance }\end{array}$ & $\begin{array}{l}\text { Leistungen an Vermieter (So- } \\
\text { zialwohnungen) und an Mieter } \\
\text { zusätzlich zu anderen Sozial- } \\
\text { leistungen }\end{array}$ & $\begin{array}{l}\text { Leistungen an Ver- } \\
\text { mieter (Sozialwoh- } \\
\text { nungen); an Mieter } \\
\text { in SGB II und SGB } \\
\text { XII eingeschlossen, } \\
\text { sonst zusätzliches } \\
\text { Wohngeld }\end{array}$ \\
\hline
\end{tabular}


Das Ergebnis dieser Entwicklung lässt sich unter Benutzung eines politikwissenschaftlichen Sprachgebrauchs zusammenfassen als eine Konvergenz innerhalb einer pfadabhängigen Entwicklung. Die einzelnen rechtlich institutionellen Aspekte sind:

1. Die Feststellung von Eardley et al. 1996, ${ }^{70}$ das UK und z. T. auch Deutschland gehörten zum Typus „breites, integriertes Basissystem der social assistance“ lässt sich 12 Jahre später nicht mehr aufrecht erhalten. Vielmehr haben alle drei Länder jetzt ein „Zwei- oder Mehrsäulenmodell der social assistance“, das neben einem Basissystem über vielfältig gegliederte Sondersysteme verfügt. Hierbei handelt es sich um ein Beispiel symmetrischer Konvergenz: ${ }^{71}$ Frankreich entwickelte ein Basissystem, UK und Deutschland entwickelten Sondersysteme und alle drei entwickeln vor allem Sondersysteme für Erwerbsfähige.

2. In allen drei Ländern konzentrieren sich die allgemeinen Auffangsysteme der „social assistance" zur reinen Armutsbekämpfung auf die Nichterwerbsfähigen und spielen nur noch eine geringe Rolle. Basissysteme sind angesichts der Lücken der Systeme der Sozialversicherung und der Sondersysteme der „social assistance“ aber notwendig, wie die Entwicklung in Frankreich zeigt, das erst 1988 mit dem RMI ein allgemeines Auffangsystem schuf. Aber anders als ,income support“ und SGB XII werden Leistungen des RMI nicht - wie die alten Systeme - ,voraussetzungslos“ und im wesentlichen nur mit dem Ziel der Existenzsicherung geleistet, sondern verlangen in sehr flexibler Weise (unten V) als „Gegenleistung“ die Integrationsbereitschaft und ist eng mit entsprechenden zusätzlichen Integrationsmaßnahmen verbunden.

3. Sondersysteme haben entsprechend ihrer immanenten Logik unterschiedliche Voraussetzungen (die besonderen Bedarfe als Leistungsfall) und dann oft auch unterschiedliche Leistungen. Selbst die sehr allgemeinen deutschen Systeme SGB II und XII haben Sonderregelungen für Mütter, Alleinerziehende, Behinderte und Alte.

4. Um Inkonsistenzen zwischen den Systemen zu vermeiden, den politischen Druck nach Vereinheitlichung zu mildern und den Anforderungen der Gleichbehandlung zu genügen, sind die abgrenzenden Begriffe wie „Erwerbsfähigkeit“ oder „Arbeitsbereitschaft" abgestimmt und gibt es einen allgemeinen Mindestbetrag für alle ,social assistance" Leistungen; beides aber nur in Deutschland und im UK, nicht in Frankreich. Bisher wird nur im UK diskutiert, alle „social assistance“-Leistungen zu vereinheitlichen. ${ }^{72}$

5. Angesichts der Dominanz des besonderen Sicherungszwecks ist es nicht verwunderlich, dass in Frankreich (traditionell) und UK (neuerdings) die Verzahnung zu den Sozialversicherungsleistungen von den Voraussetzungen und der Administration her sehr eng ist. Auch Deutschland hat - bei strikter Trennung von Sozialhilfe und Sozial-

70 Eardley et al., Social Assistance in OECD-Countries (Fußn. 18), S. 169.

71 Terminologie bei Martin Seeleib-Kaiser, Wohlfahrtssysteme unter Bedingungen der Globalisierung. Divergenz, Konvergenz oder divergente Konvergenz?, Zeitschrift für Sozialreform 1999, S. 3.

72 Freud Report, Dept. of Work and Pensions, 2007, S. 99 ff. 
versicherung - eine engere Abstimmung in den Voraussetzungen eingeführt (dazu unten IV).

6. Es gibt im UK und Frankreich zwei Sondersysteme für die Erwerbsbevölkerung: (1) für ,arme“ Erwerbstätige und (2) für arbeitslose und/oder behinderte Erwerbsfähige. Nur Deutschland macht diese Trennung nicht deutlich mit, sondern hat nur ein ,social assistance" System für die ganze Erwerbsbevölkerung (SGB II). Das deutsche SGB II ist - in starkem Unterschied zu UK - insoweit auch allgemeiner, als es die Leistungen für Kinder und den Wohnbedarf integriert; in abgeschwächter Form trifft dies auch auf das RMI zu.

7. Der staatliche Interventionspunkt „Bedürftigkeit“ wird rein instrumentell nicht mehr am Existenzminimum, sondern nur noch am „Einkommensmangel“ orientiert, vor allem um Anreize zur Aufnahme einer Erwerbsarbeit zu schaffen oder besonderen Bedarfen gerecht zu werden. Deshalb gehen die Leistungen ,arme“ Erwerbstätige und besondere Bedarfe weit über das Niveau der allgemein akzeptierten Grenze materieller Armut hinaus.

8. Systematisch-analytisch verliert die Unterscheidung zwischen „social assistance“ einerseits und Vorsorgesystemen andererseits an Relevanz vor allem in Frankreich und UK, die neben der Sozialversicherung immer ihr zugeordnete Sondersysteme der ,social assistance“ kennen. Die Besonderheit der „social assistance“ reduziert sich auf die Bedürftigkeitsprüfung.

\section{Veränderungen in der Grundstruktur}

\section{Personeller Geltungsbereich: Migranten von außerhalb der EU}

Von ihrer Grundfunktion her soll die „social assistance“ das Existenzminimum sichern, das an sich jedem Menschen zusteht; seine Versagung würde die Würde des Menschen verletzen. Bis in die 80er Jahre des vorigen Jahrhunderts waren in allen drei Ländern die Leistungen der allgemeinen ,social assistance“ nur an den (schlichten, nicht nur vorübergehenden) Aufenthalt im jeweiligen Land geknüpft. ${ }^{73}$ Angesichts der Ausdifferenzierung der „social assistance“ und ihre Zurichtung auf besondere Gruppen verwundert es nicht, dass in allen drei Ländern ab $1990^{74}$ für die „unerwünschten“ Einwanderer (Asylbewerber) Sondersysteme geschaffen werden, deren Niveau weit unter dem der üblichen ,social assistance“ liegt. ${ }^{75}$ Insoweit verliert auch das Basissystem sei-

73 Wikeley, The Law of Social Security (Fußn. 12), S. 232/3 und $280 \mathrm{f}$.

$74 \mathrm{Zu}$ früheren Ansätzen Eardley et al., Social Assistance in OECD-Countries (Fußn. 18), S. 60/61.

75 Sect. 95 Immigration and Asylum Act 1999 und Peter Billings, Alienating Asylum Seekers: Welfare Support in the Immigration and Asylum Act 1999 (2002), 9 Journal of Social Security Law, S. 115; Asylbewerberleistungsgesetz 1993; allocation temporaire d'attente (ATA) Code du travail 
nen „universellen“ Charakter und wird zur Steuerung der Einwanderung, d. h. zur Abschreckung der Masseneinwanderung via Asyl, ${ }^{76}$ instrumentalisiert. Der Aufenthaltsstatus bestimmt den „social assistance“ status. Die „social assistance“ wird vom Menschenrecht und der Garantie der Menschenwürde explizit abgekoppelt. Und hier hat sich auch der letzte Rest eines „rechtlosen“ „,social assistance“ Status bewahrt: Im UK 77 werden die Leistungen an einen Teil der Asylbewerber noch rein nach Ermessen vergeben.

Auch die anderen Migranten, die keinen gefestigten Aufenthaltsstatus haben, werden ausgegrenzt, weil durchgängig für ,social assistance“ Leistungen nicht nur der schlichte, sondern der „gewöhnliche“, d. h. der nach dem Ausländerrecht zulässige (Dauer-) Aufenthalt verlangt wird. ${ }^{78}$

\section{Personeller Geltungsbereich: Messung der Erwerbsfähigkeit}

\section{a) Wachsende Bedeutung der Leistungen an Behinderte/Erwerbsunfähige}

Im internationalen sozialpolitischen Vergleich ${ }^{79}$ wird ein allgemeiner Trend zur wachsenden Bedeutung der Leistungen an Behinderte/Erwerbsunfähige festgestellt, den drei Elemente kennzeichnen sollen:

1. Dort, wo es zwei Leistungsstränge gibt, Fürsorge und Sozialversicherung, gewinnen die Fürsorgesysteme (wieder) an Bedeutung;

Artikel L5423-8, R5423-31ff.; Décret no. 2006-1380 v. 13.11.2006 und Catherine Sebbah, La protection sociale des travailleurs étrangers en France, Revue pratique de droit sociale 2008, S. $113 \mathrm{ff}$.

76 Dazu die sozial- und ausländerpolitisch vergleichende (USA, Deutschland, Schweden) Untersuchung Diane Sainsbury, Immigrants' social rights in comparative perspective: welfare regimes, forms of immigration and immigration policy regimes, Journal of European Social Policy, 2006, S. 229.

77 Sie hängt damit zusammen, dass Anspruch auf reduzierte Leistungen nur die Asylbewerber haben, die gleich nach Zutritt (entry) zum Staatsgebiet einen Asylantrag stellen. Social Security (Persons from Abroad) Miscellaneous Amendments Regulation 1996 (SI 1996/30), die die IS (General) Regulations 1987 (SI 1987/1967) änderten. Dies hat rechtlich keinen Bestand: vgl. House of Lords Kola v. Secretary of State for Work and Pensions (2007) UKHL 54 v. 24. Nov. 2007, Journal of Social Security Law 2008, D 46/7.

78 UK: Sect. 115 Immigration and Asylum Act 1999 subsect (3) und (9). Dazu: Lydia Morris, New Labour's Community of Rights: Welfare, Immigration and Asylum, Journal of Social Policy (2007), 36, S. 39; Wikeley, The Law of Social Security (Fußn. 12), S. 232 f., 280 f., 313 f. „Habitual residence“. dazu Robin C. A. White, Residence, Benefit Entitlement and Community Law (2005), 12 Journal of Social Security Law, S. 10. Deutschland $§ 7$ Abs. 1 S. 2 und 8 SGB II. Eine Aufenthaltserlaubnis mit Zugang zum Arbeitsmarkt gibt es auch für geduldete Personen $\S \S 104$ a und b AufenthG; ansonsten generell § 39 AufenthG; Frankreich: RMI „Régularité de la séjour en France“ allg. seit 1999 vgl. Borgetto/Lafore, Droit de l'aide et de l'action sociales (Fußn. 7), S. 58 ff. Rdnr. 69; bei den minima sociaux grenzt die Anbindung an den Sozialversicherungsstatus aus.

79 OECD, Transforming Disability into Ability, Paris 2003, S. 58 ff., 64, 73 ff., 119 ff. 
2. die Anzahl der Leistungsempfänger von Behindertenleistungen und die Verweildauer in diesen Leistungssystemen nimmt zu;

3. parallel dazu werden die Aspekte der Aktivierung und Reintegration zunehmend stärker betont.

Diese Entwicklung lässt sich auch in den Rechtsstrukturen finden.

Das erste Element wurde schon bestätigt (o. 0), das dritte wird weiter unten (V) behandelt. Das zweite Element, das Wachstum der Leistungsbezieher, wird wesentlich von jenen rechtlichen Kriterien gesteuert, die bestimmen, wann eine Person noch als „erwerbsfähig“ und nicht als „,behindert“/,erwerbsunfähig“ gilt und deshalb (nur) die Leistungen für Erwerbsfähige erhält. Um diese rechtlichen Kriterien geht es im Folgenden.

Dabei sorgt gerade die Abgrenzung zu den Systemen für Behinderte für eine sehr unterschiedliche Verteilung der Arbeitslosen. Publikationen der OECD ${ }^{80}$ wie auch deutscher Autoren, ${ }^{81}$ weisen z. B. darauf hin, dass das sehr weite System des SGB II sehr viele Leistungsgeminderte zu den Arbeitslosen zählt, während im UK die gleichen Personen nicht als Arbeitslose, sondern als Behinderte in Sondersysteme eingeordnet werden.

\section{b) Funktionale Vielfalt der Kriterien zur Bestimmung einer Behinderung/ Erwerbsunfähigkeit}

Die Definitionen und Grenzziehungen sind äußerst komplex. ${ }^{82}$

a) Einmal wird Behinderung und Erwerbsfähigkeit im Kontext des Diskriminierungsrechts und des allgemeinen (arbeitsrechtlichen) Behindertenrechts (mit Beschäftigungssicherheit und -quoten etc.) definiert. Grob gesprochen ist diese Definition meist sehr weit und da nicht auf ein bestimmtes Leistungssystem, sondern auf die allgemeine Stellung in der Gesellschaft und den Arbeitsmarkt bezogen, meist ein offener Begriff, der sich stark an den Kriterien der allgemeinen, international akzeptierten Definition (ICF

80 OECD (Fußn. 79); Jochen Clasen et al., Non-employment and the welfare state, UK and Germany compared, London Anglo-German Foundation for the Study of Industrial Society, Sept. 2004, S. 18 ff.

81 Regina Konle-Seidl/Kristina Lang, Erwerbsfähige Transferbezieher im internationalen Vergleich: Von der Ausgliederung zur Integration in den Arbeitsmarkt, BArbl 10-2006, S. 14 ff.; Marcel Erlinghagen/Lina Zink, Arbeitslos oder erwerbsunfähig?, Köln. Zeitschr. f. Soziologie 2008, S. 579 ff.

82 Deborah Mabbett, Definitions of Disability in Europe, A comparative Analysis, in: European Commission Directorate-General for Employment and Social Affairs Unit E 4 (Hrsg.), 2002, S. 35 55; die Diskrepanz wird schon innerhalb des Berichts deutlich: Für Deutschland und Frankreich wird die Erwerbsminderungsrente und für Frankreich die AHH analysiert, für England die allgemeinen Leistungen bei Pflegebedürftigkeit (disability living allowance). Felix Welti, Behinderung und Rehabilitation im Sozialen Rechtsstaat, Tübingen 2005, S. 1-116. 
der WHO $)^{83}$ orientiert und sehr flexibel unterschiedliche Fähigkeiten, nicht nur solche zur Erwerbsarbeit, misst. ${ }^{84}$

b) Zum anderen geht es innerhalb des Sozialleistungssystems um die Abgrenzung gegenüber (1) den Sozialversicherungs- oder Staatsbürger-Leistungen an Erwerbsunfähige, ${ }^{85}$ die nicht von Bedürftigkeit abhängen, und (2) die Abgrenzung zwischen den allgemeinen „social assistance“ Leistungen und jenen an Behinderte, an Erwerbsunfähige sowie an Pflegebedürftige, da die Sondersysteme meist großzügiger als die normalen Leistungen sind (höhere Leistungen und Freibeträge für Einkommen und Vermögen). Essentiell ist die Abgrenzung auch für die hier besonders interessierenden ,social assistance" Leistungen an Erwerbsfähige, da hier die Abgrenzung immer einen Bezug zur (potentiellen) Erwerbsfähigkeit und zum Arbeitsmarkt hat, also funktional sein muss.

\section{c) Abgrenzungskriterien}

Es gibt keine übereinstimmende Begriffsbildung für das zweite Abgrenzungsproblem innerhalb der Sozialleistungssysteme. Hier differenziert man nach dem allgemeinen Sprachgebrauch zwischen der allgemeinen Behinderung und der auf ihr aufbauenden Erwerbsminderung, die eher funktional auf die Fähigkeit zur Erwerbsarbeit ausgerichtet ist.

\section{(1) UK}

Im UK ${ }^{86}$ verwenden fast alle Leistungsgesetze für Behinderte wie Nichtbehinderte den einheitlichen, sehr weiten Begriff der „Leistungsunfähigkeit“ (,incapacity“) und ein einheitliches, allgemeines Verfahren. Festgestellt wird die Behinderung in den ersten 28 Wochen durch die Diagnose des behandelnden Arztes etc. über die Fähigkeit, den vorherigen Beruf auszuüben (,own occupation test“), danach auf einem Assessment ${ }^{87}$, das

83 Dazu Welti, Behinderung und Rehabilitation im Sozialen Rechtsstaat (Fußn. 82), S. 63 ff.; OECD, Transforming Disability into Ability (Fußn. 79), Annex 1 S. 179 ff.

$84 \mathrm{Zu}$ diesen Anforderungen Welti, Behinderung und Rehabilitation im Sozialen Rechtsstaat (Fußn. 82), S. 113. Die notwendigen 15 Punkte erreicht z.B., wer nicht mehr als zwei Stufen steigen oder wer nicht ohne große Furcht normale Aktivitäten, wie neue soziale Kontakte, aufnehmen kann.

85 Vgl. die Übersicht bei OECD, Transforming Disability into Ability (Fußn. 79), S. 28 ff., 58 ff., $72 \mathrm{ff}$. und MISSOC.

86 Zuerst eingeführt mit der Schedule to the Social Security (Incapacity for Work) (General) Regulations 1995, Nr. 311, z.B. abgedruckt in CPAG, Welfare benefits and tax credits handbook 2007/2008, London 2007, Appendix 4, S. 1424 ff. Gemäß Welfare Reform Bill 2007, Part 1, Clause 8 durch Regulation (Dept. Of Work and Pensions, Welfare Reform Bill, Draft Regulations and supporting material, 2007) liegt sie auch der neuen „employement and support allowance“ in modernisierter Form zu Grunde.

87 Personal Capability Assessment. $\mathrm{Zu}$ ihm $C P A G$, Welfare benefits and tax credits handbook (Fußn. 86), Chapter 28, S. 668 ff. 
die physischen und geistigen Beeinträchtigungen an der Fähigkeit zu allgemeinen physischen und sozialen Aktivitäten misst. Damit ist das System gespalten. Eine an der früheren Tätigkeit orientierte, also auch den beruflichen Status schützende, pragmatisch durch den behandelnden Arzt festgestellte Arbeitsunfähigkeit für das erste halbe Jahr, in dem die Chance einer Reintegration in den alten Beruf noch groß ist, einerseits und eine sich daran anschließende umfassende Beurteilung des allgemeinen Leistungsvermögens für alle Sozialleistungszweige durch eine Behörde 88 andererseits.

Das Assessment ist sehr abstrakt und stellt es nicht auf die Fähigkeit zu bestimmten Arbeiten oder gar die Anforderungen des Arbeitsmarkts ab, ${ }^{89}$ sondern orientiert sich an den Kriterien der allgemeinen, international akzeptierten Definition (ICF der WHO) ${ }^{90}$ und misst sehr flexibel unterschiedliche Fähigkeiten, nicht nur solche zur Erwerbsarbeit. ${ }^{91}$ Alle Einschränkungen werden in ein Punkteschema übertragen und addiert. Wer 15 Punkte erreicht, gilt als „behindert“ und erhält keine Leistungen bei Arbeitslosigkeit oder „social assistance“ (für spezielle Gruppen), sondern Leistungen für Erwerbsunfähige. Dadurch ist die Abgrenzung recht scharf. Deshalb verwundert es nicht, dass in vergleichenden Studien das UK dadurch hervorsticht, dass Behinderte meist nur eine Leistung beanspruchen können und Überschneidungen zwischen Leistungen für arbeitslose Erwerbsfähige und Behinderte so gut wie nicht vorkommen. ${ }^{92}$

Eine Grenze nach der Fähigkeit, noch eine bestimmte Zeit pro Tag oder Woche zu arbeiten, spielt nur eine begrenzte Rolle, dadurch dass eine Person (weiterhin) als erwerbsunfähig gilt, die a) noch Arbeit zu einem Entgelt unterhalb von $20 £ /$ Woche, das sind zum Mindestlohn ca. 5 Std./Woche, ausübt, oder b) bis zu insgesamt 52 Wochen nicht mehr als 16 Std./Woche dauert und bis zu $86 £$ /Woche einbringt und der ein vorheriger Leistungsbezug und/oder eine Unterbrechung der Vollarbeit vorausgegangen ist, die also dazu dient, die Arbeitsfähigkeit zu stabilisieren, wieder herzustellen oder in Vollarbeit über zu gehen. ${ }^{93}$

88 Medical Service des Department for Work and Pensions, der an eine private Firma vergeben ist. Vgl. CPAG, Welfare benefits and tax credits handbook (Fußn. 86), Chapter 28, S. 669.

89 Daran knüpft auch die Kritik im UK an: Richard Berthoud, Disabled People and Jobs, (2003) Benefits 11, S. 169.

90 Dazu Welti, Behinderung und Rehabilitation im Sozialen Rechtsstaat (Fußn. 82), S. 63 ff.; OECD, Transforming Disability into Ability (Fußn. 79), S. $179 \mathrm{ff}$.

$91 \mathrm{Zu}$ diesen Anforderungen Welti, Behinderung und Rehabilitation im Sozialen Rechtsstaat (Fußn. 82), S. 113. Die notwendigen 15 Punkte erreicht z.B., wer nicht mehr als zwei Stufen steigen oder wer nicht ohne große Furcht normale Aktivitäten, wie neue soziale Kontakte, aufnehmen kann.

92 OECD, Transforming Disability into Ability (Fußn. 79), S. 45 ff.

93 Social Security (Incapacity for Work) (General) Regulations 1995, Reg. 17. CPAG, Welfare benefits and tax credits handbook (Fußn. 86), Chapter 28, S. 671/2; David Bonner/Ian Hooker/Robin White, Social Security legislation 2007, Vol. I, Non Means Tested Benefits, London 2007, Rdnr. 8.124. 


\section{(2) Deutschland}

Deutschland hat eine einheitliche begriffliche Definition der Abgrenzungskriterien für alle „social assistance“ Systeme und den wesentlichen Zweig der Sozialversicherung für Erwerbsunfähige vorgenommen ${ }^{94}$ : Erwerbsfähig ist die Person, die auf absehbare Zeit ${ }^{95}$ noch drei Stunden am Tag und mehr allgemein erwerbsfähig sein kann; wer es nicht ist, erhält entweder die Erwerbsminderungsrente der Sozialversicherung (bezogen auf die frühere Beitragsleistung, SGB VI) oder die Leistung der Grundsicherung für Erwerbsgeminderte der allgemeinen „social assistance“ (SGB XII). Die Rentenversicherungsträger orientieren sich konkreter als im britischen System an den einzelnen arbeitsbezogenen Fähigkeiten (z. B. Fähigkeit zu leichten Tätigkeiten im Sitzen). Sie akzeptieren den ICF zwar als maßgeblich zur Bestimmung der funktionalen Leistungsfähigkeit, ${ }^{96}$ halten aber für die Bestimmung der Erwerbsfähigkeit an dem direkteren Bezug auf Tätigkeiten und den Arbeitsmarkt fest. 97 Zudem gibt es weder einen allgemeinen Konsens darüber, wann der Schwellenwert von 3 Std./Tag erreicht ist; unter Fachleuten ist unbestritten, dass sich Leistungseinschränkungen auch wenn sie auf konkrete Tätigkeiten bezogen werden nur sehr schwer in Arbeitsfähigkeit für bestimmte Stunden pro Tag umrechnen lassen. ${ }^{98}$ Noch existieren gar übergreifende und bindende Kriterien für die anderen Leistungsträger oder einheitlichen Grundsätze für das Verfahren zur Feststellung der Erwerbs(un)fähigkeit.

Eine Koordination zwischen der „social assistance“ für Arbeitssuchende und den Leistungen der Sozialversicherung findet insoweit statt, als bei abweichenden Entscheidungen zwischen den einzelnen Leistungsträgern ein vorläufig zuständiger Leistungsträger festgelegt wird und eine Einigungsstelle die endgültige, bindende Entscheidung auf der Basis ärztlicher Gutachten trifft.

\section{(3) Frankreich}

In Frankreich wird die Abgrenzung der Systeme für Behinderte wie in Deutschland nach einem Prozentsatz des allgemeinen Erwerbsvermögens vorgenommen. Für die allgemeine ,social assistance“ Leistung an Behinderte (allocation aux adultes handicapés, AAH) ist der Begriff „handicapé“ 2005 sehr offen ganz in Übereinstimmung mit dem

94 Vgl. die gleichlautende Definition in $\S \S 43$ SGB VI (Rentenversicherung), 8 SGB II und 41 Abs. 1 Nr. 2 SGB XII (Sozialhilfe).

95 Auch hier spielt die 6-Monatsgrenze eine Rolle, vgl. $§ 101$ Abs. 2 und 102 Abs. 1 SGB VI.

96 Das Schema des ICF wird im allgemeinen Behinderungsrecht (SGB IX und Antidiskriminierungsrecht) zu Grunde gelegt, vgl. Felix Welti, Das AGG: Behinderungsbegriff und praktische Konsequenzen für das Sozialrecht, SozialRecht aktuell 2007, S. 161.

97 Abschlußbericht der Kommission zur Weiterentwicklung der Sozialmedizin in der gesetzlichen Rentenversicherung (SOMEKO), DRV-Schriften Bd. 53, 2004, S. $213 \mathrm{ff}$.

98 Ebda., S. 215. 
ICF definiert worden und entsprechende Verfahren werden auch angewandt. ${ }^{99}$ Jedoch ist der Maßstab sehr grob ein Prozentsatz des vollen Arbeitsvermögens, wobei die Grenze für die dauerhafte Behinderung bei $80 \%$, im Grenzbereich von $50-80 \%$ bei einer von Sachverständigen anerkannten dauerhaften Arbeitsunfähigkeit liegt. Dagegen ist der Schwellenwert bei der Sozialversicherungsrente bei Invalidität 66,6 \% (bezogen auf das Arbeitsvermögen und/oder die Verdiensteinbuße). 100

Bei der Arbeitslosenhilfe (l'allocation de solidarité spécifique, ASS) wie beim Arbeitslosengeld stellt die Verwaltung der Arbeitslosenversicherung fest, ob der Leistungsberechtigte arbeitsfähig ist und der Arbeitsvermittlung zur Verfügung steht ${ }^{101}$ oder aber, ob er - auf welchem Niveau auch immer - zur sozialen Integration bereit ist (revenu minimum d'insertion, RMI). Gerade das RMI als sehr breite Leistung überschneidet sich deshalb mit den Leistungen an Behinderte, die konsequenterweise auf das RMI angerechnet werden. ${ }^{102}$

\section{(4) Fazit}

Die Abgrenzung zwischen der social assistance für Erwerbsfähige und den Leistungen für Behinderte hat drei Probleme zu lösen, um halbwegs stimmig zu sein:

1. Die Erwerbs(un)fähigkeit wird durch dieselben Kriterien und dieselben Instrumente in allen Sozialleistungszweigen gemessen, um Unstimmigkeiten und Sicherungslücken zu vermeiden; nur im UK wird dies realisiert, indem durchgängig die ICF der WHO zu Grunde gelegt werden. Eine solche Herangehensweise ist letztlich ,problemzentriert", im Mittelpunkt steht die Sicherung der Behinderten durch Feststellung ihrer Potentiale, um ihre Existenz abzusichern und sie in den Arbeitsmarkt und die Gesellschaft zu integrieren. Dies geht nur, wenn man auf Definitionen verzichtet, die auf die spezifischen Ziele und Voraussetzungen der einzelnen Leistungssysteme abgestellt sind.

2. Die (arbeitsmedizinischen) Einschätzungen und die darauf fußenden Entscheidungen über die Leistungen sind für alle Leistungszweige verbindlich, sei es, dass sie durch ein und denselben Dienst vorgenommen werden, wie im UK ${ }^{103}$, sei es, dass die Entscheidungen verwaltungsintern binden wie in Deutschland ${ }^{104}$; in Frankreich sind die einzelnen Zweige ganz unterschiedlichen Trägern und Diensten (Departments bzw. der

99 Code de l'action sociale et des familles Article L114; Borgetto/Lafore, Droit de l'aide et de l'action sociales (Fu ßn. 7), S. 374/5 Rdnr. 409 bis. Ähnlich weit für die Sozialversicherungsleistungen bei Invalidität Code de la sécurité sociale L341-1 und L341-3. Für die AHH galt diese Offenheit auf Verwaltungsebene auch schon vor 2005 vgl. Mabbett, Definitions of Disability in Europe (Fußn. 82), S. 116-8.

100 Code de la sécurité sociale L341-1 und L341-3.

101 „Aptes au travail et recherchant un emploi“ Code du travail art. Article L5421-1, Article L5421-3.

102 Code de l'action sociale et des familles Art. L262-10.

103 Zum einheitlichen Verfahren vgl. CPAG, Welfare benefits and tax credits handbook (Fußn. 86), Chapter 28, S. $668 \mathrm{ff}$.

104 Durch $\S \S 44 a, 45$ SGB II (innerhalb der Sozialversicherung schon traditionell durch $§ 125$ SGB III). 
privatrechtlichen Sozialversicherung) zugewiesen, ohne interne Bindung und inhaltliche Kongruenz.

3. Die Leistungssysteme für Behinderte einerseits und für Erwerbsfähige andererseits haben keine unterschiedlichen Voraussetzungen in Form von Anwartschaften etc., was im UK der Fall ist, da hier sowohl Versicherungs- wie Fürsorgesysteme für Behinderte wie für Erwerbsfähige zusammengefasst sind, während in Deutschland und in Frankreich die Sonderleistungen für Behinderte stark von der Sozialversicherung getragen werden, mit unterschiedlichen Anforderungen an Versichertenstatus und Anwartschaften.

\section{Personeller Geltungsbereich: Messung der Arbeitsmarktbeteiligung bei Leistun-} gen an Niedrigverdiener

Komplex ist auch das Abgrenzungsproblem, wenn die „social assistance“ Leistungen an Beschäftigte nach dem Grad der Integration in den Arbeitsmarkt unterschieden werden, wie in Frankreich und UK. In Deutschland ist das allgemeine „social assistance“ System für Erwerbsfähige (SGB II) für jeden Erwerbsfähigen zuständig, unabhängig davon, ob er/sie arbeitet oder nicht und wenn er arbeitet, wie viele Stunden in der Woche. Wer als Halbtagsbeschäftigter Leistungen nach dem SGB II erhält, muss auch bereit sein, sein Arbeitsvermögen voll auszuschöpfen, also eventuell Vollzeit zu arbeiten um seine Abhängigkeit von öffentlichen Leistungen zu beenden. ${ }^{105}$ Die speziellen in das Steuersystem integrierten bedürftigkeitsabhängigen Leistungen an Erwerbstätige im UK und in Frankreich sollen an die ,working poor" gehen. Sie verzichten auf einen Test der vollen Arbeitsfähigkeit und Arbeitsbereitschaft. Sie sind letztlich Subventionen eines zu niedrigen Stundenlohns, nicht Leistungen wegen partieller Arbeitslosigkeit. Dann müssen sie sich aber auch auf dieses Ziel konzentrieren und jene Fälle ausscheiden, bei denen die Ursache des niedrigen Einkommens nicht der niedrige Marktlohn, sondern die niedrige Zahl der Arbeitsstunden ist. Sie müssen also eine Vorstellung entwickeln, wer im unterstützungswürdigen Maße im Arbeitsmarkt integriert ist.

Stark typisierend geht hier das UK vor. (Working) Tax credits erhält nur, wer entweder mindestens $30 \mathrm{Std}$./Woche arbeitet oder wer mindestens $16 \mathrm{Std}$./Woche arbeitet, wenn er/sie über 50 Jahre alt ist, oder ein Kind oder eine pflegebedürftige Person versorgt oder behindert ist. ${ }^{106}$ Die unterschiedliche Beteiligung am Arbeitsmarkt wird über die Grenze, bis zu der das Arbeitseinkommen aufgestockt wird, berücksichtigt; sie erhöht sich für die einzelnen Personengruppen unterschiedlich stark.

In Frankreich wird die im Vergleich zum UK niedrige PPE erst ab einer Halbtagsbeschäftigung geleistet und dann auch mit geringeren Beträgen als für eine Vollzeitbe-

$105 \S \S 2,3,9$ Abs. 1 und 10 SGB II.

106 Regulation 4 Working Tax Credit (Entitlement and Maximum Rate) Regulations 2002, SI 1002/2005. CPAG, Welfare benefits and tax credits handbook (Fußn. 86), Chapter 49, S. 1226 ff. 
schäftigung; besondere Vergünstigungen für spezielle Bedarfstypen gibt es nicht. Sie setzt auch voraus, dass man mindestens $3743 €$ im Jahr verdient, also in etwa die deutsche Grenze einer geringfügigen Beschäftigung überschreitet. 107

\section{Selbständiger Arbeitsmarktbürger und Bedarfsgemeinschaft}

Ist Adressat der Leistungen in den besonderen Systemen der „social assistance“ der Erwerbsfähige oder gar der Erwerbstätige, so ist Leitbild eine Person, die für sich selbst verantwortlich ist und die sich selbst durch eigenes Markteinkommen unterhält.

\section{a) Individueller Anspruch/Familienanspruch}

Mit dem Leitbild des Arbeitsmarktbürgers ist nicht mehr vereinbar und würde zudem dem Grundsatz der Gleichbehandlung nach dem Geschlecht ${ }^{108}$ und dem neueren Familienrecht der vollen Gleichberechtigung beider Partner widersprechen, eine Person meist den Ehegatten - zum Haushaltsvorstand zu erheben und ihr einen höheren Grundbetrag oder ihr sonst eine privilegierte Stellung z. B. im Verwaltungsverfahren zu geben. Entsprechende explizite Regelungen finden sich deshalb in keinem der drei Länder mehr. Wegen der engen Verbindung zum Diskriminierungsverbot gilt dieser Grundsatz allerdings auch für die allgemeine „,social assistance“. Ganz strikt geht hier $\S 20$ Abs. 3 SGB II vor: Bei zwei Partnern wird der ihnen zustehende gemeinsame Bedarfssatz auch genau zwischen ihnen geteilt.

Aber die Ausnahme von diesen Grundsätzen sind zahlreich. Eher verwaltungspraktisch begründet ist die Vertretungsfiktion bei „Bedarfsgemeinschaften“ im deutschen Recht ( $\$ 38$ SGB II). Danach kann das Verwaltungsverfahren mit nur einer Person geführt werden, es wird vermutet, dass der erwerbsfähige Hilfebedürftige bevollmächtigt ist, auch die Ansprüche der Mitglieder seiner Bedarfsgemeinschaft geltend zu machen. Das UK überlässt es den Anspruchsberechtigten, ob sie gemeinsam oder einer von ihnen die Ansprüche geltend machen; ${ }^{109}$ ein ,joint-claim“ ist nötig für Paare bei der jobseekers's allowance, wenn beide die Voraussetzungen erfüllen und dann auch beide arbeitsbereit etc. sein müssen. 110

$107 \mathrm{http} / /$ www.travail-solidarite.gouv.fr/informations-pratiques/fiches-pratiques/remuneration/primepour-emploi-ppe.html?var_recherche=PPE.

108 Vgl. Karl-Jürgen Bieback, Family Benefits - The New Legal Structures of Subsidising the Family, (1992) 2 Journal of European Social Policy, S. 239, $245 \mathrm{ff}$.

$109 C P A G$, Welfare benefits and tax credits handbook (Fußn. 86), Chapter 13, S. 298; 15, S. 375-7; S. 30; S. $711 \mathrm{ff}$.

110 Sect. 1 (2B) und (4) Jobseekers Act 1995; Reg 3A (1) Jobseeker's Allowance Regulations 1996 SI 1996/207. Näheres bei CPAG, Welfare benefits and tax credits handbook (Fußn. 86), Chapter 15, S. $375 \mathrm{ff}$. 
Anders ist es in Frankreich. Hier erhält der Anspruchsberechtigte, der die Voraussetzung für die minima sociaux (früherer Versichertenstatus oder gegenwärtiger Bezug einer Versicherungsleistung) oder das RMI erfüllt, auch die Zuschläge für den Partner und evtl. die Kinder, da diese rechtstechnisch nur Berechnungsfaktoren seines Anspruchs sind. ${ }^{111}$ Soweit ersichtlich, wird dies in der französischen Sozialrechtsliteratur nicht problematisiert.

\section{b) Feststellung des Bedarfs - Individuen oder Bedarfsgemeinschaft}

Alle drei Länder folgen in Übereinstimmung mit der allgemeinen Armuts- und Bedarfsforschung 112 der Erkenntnis, dass mehrere Personen, die zusammen leben, niedrigere Haushaltskosten haben als Einzelpersonen und senken dementsprechend den Satz für zwei zusammenlebende Personen entsprechend ab, allerdings in sehr unterschiedlichem Maße. 113

Damit zusammen hängt die Frage, wie die „Bedarfsgemeinschaft“ bestimmt wird, wenn mehrere Personen zusammen leben. Dies ist für bedürftigkeitsgeprüfte Leistungen in soweit unproblematisch, als immer vom tatsächlichen Bedarf auszugehen ist. Wer aus welchen Gründen auch immer - bei anderen Personen mietfrei wohnt, wird keinen Anspruch auf „social assistance“ Leistungen für die Unterkunft haben. Nach welchen Prinzipien geht man aber vor, wenn der Bedarf nicht „automatisch“ befriedigt wird, sondern mehrere Personen nur „einfach“ zusammenleben? Rechtlich gibt es hierfür nur zwei Anknüpfungspunkte: (1) der gemeinsame Haushalt und/oder (2) die Familie.

Das UK und Frankreich kombinieren beide Kriterien:114 Voraussetzung ist einmal ein Zusammenleben im gemeinsamen Haushalt und zweitens die Zusammengehörigkeit in der „Kernfamilie“ als Paare (Verheiratete, Partnerschaften und zusammenlebende Paare), Kinder nur wenn die Anspruchsberechtigten für sie aufkommen müssen. ${ }^{115}$ Soweit zwei Personen unterschiedlichen Geschlechts zusammenleben sind die Anforderungen und Feststellungen hochkomplex; dem kann hier nicht näher nachgegangen werden.

In England ${ }^{116}$ und in Frankreich ${ }^{117}$ werden die Partner, die bei der Feststellung des Bedarfs zu berücksichtigen sind, in den Pflichtenkreis mit einbezogen, so dass auch sie

111 Vgl. für das RMI L262-2, R262-1 und 14 Code de l'action sociale et des familles.

112 Berechnet in der Armutsforschung über die sog. Äquivalenzskalen, vgl. 1. Armutsbericht der Bundesregierung, Deutscher Bundestag, BT-Drs. 14/5990, S. 29.

113 Von $90 \%$ des Satzes für einen Alleinstehenden in Deutschland ( $§ 20$ Abs. 3 SGB II) über $63.7 \%$ (59.15 £ als Alleinstehender zu $92.80 £$ pro Woche als Paar: http://www.jobcentreplus.gov.uk/ jcp/Partners/Allowancesandbenefits/Dev_009943.xml.html) zu nur noch $50 \%$ für die zweite Person beim RMI in Frankreich (http://www.travail-solidarite.gouv.fr/IMG/xls/RMIbareme2008.xls).

114 Gough et al., Social Assistance in OECD-Countries (Fußn. 19), S. 29, behandeln Haushalt und Familie als distinkte, einander ausschließende Zuordnungspunkte.

115 Vgl. Fußn. 109, 110, 111.

116 Fußn. 110. 
arbeits- oder eingliederungsbereit sein müssen und mit ihnen eine Eingliederungsvereinbarung abzuschließen ist etc.

Deutschland geht zwar auch im SGB II von dem gemeinsamen Haushalt und der Kernfamilie aus, bezieht aber auch die Eltern, Stiefkinder und Stiefeltern eines Hilfebedürftigen ${ }^{118}$ sowie die enger mit ihm zusammenlebenden Personen ${ }^{119}$ mit ein. Auch wenn diese Personen selbst nicht bedürftig sind, ihr Einkommen und Vermögen jedoch bei der Feststellung des Bedarfs berücksichtigt wird, werden sie mit allen Rechten und vor allem auch Pflichten anspruchsberechtigt - ohne dass klar ist, wie der Ausgleich zwischen den Mitgliedern stattfinden soll. Darüber hinaus kennt Deutschland eine (widerlegbare) Vermutung, dass wenn verwandte und verschwägerte Personen zusammenleben, sie auch den jeweils Bedürftigen Unterhalt gewähren. ${ }^{120}$ Als Grund für diese weite Fassung wird nur Verwaltungsvereinfachung genannt; vermuten lässt sich eher, dass auch die anderen Mitglieder ein Interesse an der Beseitigung der Hilfebedürftigkeit haben und den Druck auf die Arbeitsmarktintegration erhöhen. ${ }^{121}$

\section{Rückgriff auf Unterhaltsansprüche - eingeschränkte Subsidiarität}

Nach dem Leitbild des Arbeitsmarktbürgers wäre auch der Rückgriff auf Unterhaltsansprüche in den besonderen Systemen für Erwerbsfähige „systemfremd“. Wer vorher sich selbst durch eigene Arbeit unterhalten und deshalb nicht auf Unterhaltsansprüche gegen andere zurückgegriffen hat und wer auf diesen Status hin re-orientiert werden soll, bei dem wäre es nur konsequent, auch in der Unterstützungsphase Unterhaltsansprüche nicht zu berücksichtigen, ihn als eigenständiges Individuum zu behandeln. Aber hier kommt ein klassisches Prinzip der „social assistance“ ins Spiel, das Subsidiaritätsprinzip und der Vorrang anderer Ressourcen, zu denen auch Unterhaltsansprüche gehören. Das gibt eine Gemengelage, in der unterschiedliche Prinzipien optimiert werden müssen.

Ganz dem Leitbild des individuellen, selbständigen Arbeitsmarktbürgers folgt die negative Einkommenssteuer in England und Frankreich. ${ }^{122}$ Sie knüpft an die individuel-

117 Article L 262-2 und L262-37 Code de l'action sociale et des familles: «l'allocataire et les personnes prises en compte pour la détermination du montant de cette allocation ... doivent conclure un contrat d'insertion».

$118 \S \S 7$ Abs. 3 SGB II. Dazu: Wolfgang Spellbrink, Die Bedarfsgemeinschaft gemäß $§ 7$ SGB II eine Fehlkonstruktion?, NZS 2007, S. 121. Vom BSG für rechtmäßig angesehen: BSG v. 7.11.06 - B 7b AS 8/06 - SozR 4-4200 § 22 Nr. 1.

$119 \S \S 7$ Abs. 3 Nr. 3c und Abs. 3a SGB II. Dazu Frauke Brosius-Gersdorf, Bedarfsgemeinschaften im Sozialrecht, NZS 2007, S. 410.

$120 \S 9$ Abs. 5 SGB II.

121 Spellbrink (Fußn. 118), NZS 2007, S. 123.

122 Siehe zu Frankreich: http://www.travail-solidarite.gouv.fr/informations-pratiques/fiches-pratiques/ remuneration/prime-pour-emploi-ppe.html?var_recherche=PPE (31.5.2008). Für England : $C P A G$, 
le Besteuerung des jeweiligen Einkommens des/der Erwerbstätigen an und berücksichtigt etwaige Unterhaltsansprüche gegenüber Dritten nicht. Mit einer Ausnahme. Obwohl die Besteuerung individuell ist, wird zum Zweck der Berechnung der negativen Einkommenssteuer das Einkommen zusammenlebender Paare (und eventuell der mit ihnen zusammenlebenden Kinder) zusammengerechnet und erst dieses Einkommen dann an einem Bedarfssatz gemessen und eventuell aufgestockt.

Die sonstigen ,social assistance“ Leistungen gehen von der traditionellen, erweiterten Bedürftigkeitsprüfung aus. Unbestritten ist in allen drei Ländern, dass Unterhalt, der tatsächlich gezahlt wird, auch bei der Bedürftigkeitsprüfung zu berücksichtigen und als Einkommen anzurechnen ist. Ansonsten ist hier alles im Fluss, was teilweise auch von den unterschiedlichen Regimen des Unterhaltsrechts abhängt. ${ }^{123}$

Im französischen „social assistance“ Recht spielt der Rückgriff auf Unterhaltsansprüche nur noch eine begrenzte Rolle. ${ }^{124}$ Für das RMI ${ }^{125}$ werden nur Ansprüche gegenüber Ehegatten und früheren Ehegatten sowie Eltern und minderjährigen Kindern berücksichtigt; aber auf Antrag kann der Berechtigte befreit werden, sie geltend zu machen. ${ }^{126}$ In Frankreich scheint es akzeptiert zu sein, dass an die Stelle der familiären Solidarität (ausschließlich) die der Nation getreten ist. 127

Im UK sind Unterhaltsansprüche nur zwischen Eltern und Kindern bis 20 Jahren und zwischen Ehepartnern und Partnern einer eingetragenen Lebensgemeinschaft anzurechnen und können von der Verwaltung gegen den Unterhaltsverpflichteten geltend gemacht werden. 128

Auch in Deutschland wird der Unterhalt zwischen Ehegatten und Partnern noch voll, der zwischen Eltern und Kindern (in beiden Richtungen) nur noch begrenzt berücksichtigt; Unterhaltsansprüche, die nicht geltend gemacht werden, werden nicht auf die Verwaltung übergeleitet. 129

In Deutschland und Frankreich verlieren mit dem Übergang zu speziellen ,social assistance" Systemen für Erwerbsfähige die Unterhaltsansprüche zwischen Eltern und volljährigen Kindern ihre Bedeutung. Insoweit setzt sich hier die Vorstellung des selbständigen Arbeitsmarktteilnehmers voll durch. In Deutschland dürfte auch die weite

Welfare benefits and tax credits handbook (Fußn. 86), Chapter 48, S. 1213 ff. sowie Chapter $51 \mathrm{~S}$. $1258 \mathrm{ff}$.

$123 \mathrm{Zu}$ ihnen Kirsten Scheiwe, Kinderkosten und Sorgearbeit im Recht, Frankfurt a.M. 1999, S. 82 ff., 121 ff.; Peter Dopffel/Bernd Buchhofer (Hrsg.), Unterhaltsrecht in Europa: eine Zwölf-LänderStudie, Tübingen 1983.

124 Maryse Badel, Subsidiarité et aide sociale: quelle actualité, RDSS 2007, S. 1077, 1084/5; Francis Kessler/Frédéric Géa, Le principe de subsidiarité dans le droit de l'aide sociale, in: Philippe Lignea (Hrsg.), Drôle(s) de droit(s), Melanges en l'honneur de E. Alfandari, Paris 2000, S. 303.

125 Code ASF Art. 262-35.

126 Badel (Fußn. 124), RDSS 2007, S. 1084 m.w.N. in Fußn. 43.

127 Badel und Kessler/Géa ebda.

$128 C P A G$, Welfare benefits and tax credits handbook (Fußn. 86), Chapter 32, S. 753.

$129 \S 33$ Abs. 2 Nr. 2 und 3 SGB II. 
Fassung der Bedarfsgemeinschaft (oben IV, 4, b) dazu führen, auf Unterhaltsansprüche nicht zurück zu greifen. Wer an sich nicht hilfebedürftig ist und hilfebedürftig nur über das Zusammenleben mit einem Hilfebedürftigen wird, dem er sogar noch nicht einmal unterhaltsverpflichtet sein muss, bei dem ist es kaum gerechtfertigt, nun sogar noch auf dessen eigene Unterhaltsansprüche zurückzugreifen - zumal das Zivilrecht in der Regel bei einer solchen Konstellation keinen Unterhaltsanspruch entstehen lässt.

Diese Tendenz prägt aber nicht nur die Leistungen an Erwerbsfähige, sondern auch andere spezielle „social assistance“ Leistungen. In Deutschland werden bei der Grundsicherung im Alter unterhaltsverpflichtete Kinder nur ab einem Einkommen von $100.000 € \mathrm{im}$ Jahr herangezogen. ${ }^{130}$ Noch weiter geht in Frankreich die neue „social assistance" Leistung bei Pflegebedürftigkeit über 60 (Allocation personalisée d'autonomie, APA). Bei ihr werden Unterhaltsverpflichtungen und -leistungen der Kinder nicht angerechnet und nur begrenzt auf die eigenen Ressourcen über eine Selbstbeteiligung (,ticket modérateur") zurückgegriffen. 131

Fazit: Spezielle „social assistance“ Systeme haben offensichtlich eine immanente Tendenz nicht die gesamten Ressourcen der Hilfebedürftigen heranzuziehen. Vor allem wohl auch, weil sie den besonderen Bedarf für legitimer halten als bei der allgemeinen „social assistance“. Diese Tendenz wird bei Systemen für Erwerbsfähige gestärkt, da sie auf die Integration in den Arbeitsmarkt und dem Leitbild des selbständigen Marktbürgers ausgerichtet sind, der nicht auf sich gestellt ist und nicht auf Unterhaltsansprüche zurückgreifen muss.

\section{Aufstockende Leistungen an Erwerbstätige: Von der Sicherung gegen Armut zur} Sicherung eines angemessenen Einkommens

\section{a) Armutsfallen und ,moral hazard"}

Bei Leistungen die nachrangig Arbeitseinkommen ersetzen oder aufstocken wird das Problem der „Armutsfallen“ diskutiert: Bleibt den Leistungsbeziehern beim Wechsel in Arbeit oder bei Steigerung ihres Einkommens wegen der Anrechnung des Einkommen auf die „social assistance“ kaum oder nur wenig mehr übrig als mit dem Bezug der Sozialleistung, wird zumindest der Anreiz zur Selbsthilfe geschwächt. ${ }^{132}$ „Armutsfallen“

$130 \S 43$ Abs. 2 SGB XII.

1312007 betrug die Selbstbeteiligung bei der Pflege zu Hause 90 \% des tatsächlich beanspruchten Pflegebedarfs bei einem (anrechenbaren) Einkommen oberhalb 2.669,50 €/Monat. Bei der Pflege in einem Heim werden nur die reinen Pflegekosten getragen und hier richtet sich der Selbstbehalt nach dem Grad der Hilfsbedürftigkeit und einem festen Satz (den Pflegekosten für die geringste Stufe der Pflegebedürftigkeit) plus einem bestimmten Prozentsatz dieser Kosten, der erst bei einem Einkommen über 3.339,31 $€$ sein Maximum erreicht.

132 Für eine gewisse Plausibilität: Stefan Boeters/Michael Feil, Heterogeneous labour markets in a microsimulation-AGE model, IAB Discussion Paper, 25/2008, R. Gebauer, Arbeit gegen Armut, 2007, 
sind zumindest ein Problem konsistenter Modelle und Regelungen, ob sie empirisch tatsächlich auftreten, wird bezweifelt, ${ }^{133}$ da die Entscheidung für Arbeit nicht nur von dem Ziel, über (mehr) eigenes Einkommen zu verfügen, geleitet wird.

Um durchgängig einen Anreiz zu schaffen, auch während eines Bezugs von ,social assistance“ (mehr) zu arbeiten, darf (zusätzliches) Einkommen aus Arbeit nicht voll, sondern nur zum Teil angerechnet werden. Ist die Anrechnungsquote gering, kann noch bei einem recht hohen Arbeitseinkommen „social assistance“ beansprucht werden. Das hat zwei paradoxe Ergebnisse:

(1) Das Ziel, mit der Arbeitsmarktorientierung die „social assistance“ Abhängigkeit zu senken, kehrt sich um: Die Zahl der Empfänger von „social assistance“ wächst, je sanfter die Anrechnung zusätzlichen Einkommens und je leichter der Übergang in bezahlte Arbeit ist; insbesondere wenn dies noch durch eine Politik flankiert wird, den Sektor niedriger Löhne auszudehnen und gerade für „,social assistance“ Empfänger wieder attraktiv zu machen.

(2) Der Bedürftigkeitsbezug der Leistungen erfordert an sich die Anrechnung aller Ressourcen und die Sicherung des Existenzminimums verbietet es, dass der Staat ein Einkommen über dieser Grenze unterstützt.

Es geht also um eine „Optimierung“ unterschiedlicher, im Widerstreit liegender Prinzipien der „social assistance“ für Erwerbsfähige. Alle drei Länder haben bedürftigkeitsgeprüfte Leistungen an Niedrigverdiener eingeführt ${ }^{134}$ und müssen diese Zielkonflikte lösen.

\section{b) Ein wichtiger Entwicklungsfaktor in allen drei Ländern}

Hier ist das UK Vorreiter gewesen. Traditionell ist die angelsächsische „social assistance" davon geprägt, Arbeitsanreize nicht zu zerstören und keine Alternative zum Arbeitsmarkt zuzulassen. Die Fowler Reports von $1985^{135}$ konzentrierten sich stark auf

und Sachverständigenrat zur Begutachtung der gesamtwirtschaftlichen Entwicklung, Arbeitslosengeld II reformieren: Ein zielgerichtetes Kombilohnmodell, Gutachten 2006. Allein auf der Modellebene bleibt Wissenschaftlicher Beirat beim Bundesministerium der Finanzen, „Existenzsicherung und Erwerbsanreiz", Gutachten Mai 2008.

Unter:

www.bundesfinanzministerium.de/nn_4342/DE/Wirtschaft_und_Verwaltung/Finanz_und_Wirt schaftspolitik/Wissenschaftlicher_Beirat/Gutachten_und__Stellungnahmen/Ausgewählte__ Texte/001_a_gutachten_existenzsicherung_erwerbsanreiz,templateId= raw,property=publicationFile.pdf. Insbes. S. 6 ff., $28 \mathrm{ff}$.

133 Für Frankreich: Jean-Michel Bèlorgey, Minima Sociaux, revenus d'activité, précarité, La Documentation francaise, Paris 2000. Für Deutschland und skeptisch: Ronald Gebauer/Georg Vobruba, The Open Unemployment Trap, Journal of Social Policy (2003), 32, S. 571.

134 Sachverständigenrat (Fußn. 132), S. 53-80; Herbert Düll, Arbeitsanreize im Kontext des SteuerTransfer-Systems: Ein ausgewählter internationaler Vergleich, BArbBl 4/2006, S. 4.

135 Green Paper Reform of Social Security 1985, Cmnd 9517 und White Paper Reform of Social Security 1985 , Cmnd 9691. 
dieses Problem eines ausgebauten Wohlfahrtsstaates (obwohl es auch ein Problem zu niedriger Löhne ist) und führten zum Ausbau spezieller Leistungssysteme für die ,working poor". ${ }^{136}$ Die Anrechnungsrate zusätzlichen Einkommens ist in der Sozial- und Arbeitslosenhilfe relativ hoch: nach einem Freibetrag von ca. 1/10 der Leistung wird alles (Netto-) Arbeitseinkommen angerechnet. ${ }^{137}$ Schon bei einem Einkommen auf der Basis von 16 Std./Woche wechselt man jedoch in das System der negativen Einkommenssteuer und hier wird nur $37 \%$ des Einkommens über einem Freibetrag angerechnet. ${ }^{138}$

Großzügige, vielfältige Übergangslösungen gibt es in Frankreich. ASS darf zusammen mit Wohn- und Familienleistungen und Nebeneinkommen 1.031 (Paar 1.621) $€ /$ Monat plus Zuschlägen für Kinder und Behinderungen nicht übersteigen. ${ }^{139}$ Arbeit bis zur Hälfte der üblichen Arbeitszeit und bis unter die Hälfte des monatlichen Mindestlohns (2008: $740 € /$ Monat) wird für maximal bis zu 12 Monaten Einkommen nicht angerechnet; darüber hinausgehender Verdienst zu $40 \%$ mit der Wirkung, die Anspruchsdauer zu verkürzen. ${ }^{140}$ Ähnliche Übergangsregelungen gibt es seit $2006^{141}$ bei allen bedürftigkeitsbezogenen ,social assistance“ Leistungen, wie dem RMI. Leistungsbezieher, die eine Arbeit aufnehmen, können noch für drei weitere Monate die alte ,social assistance“ Leistungen erhalten, danach noch eine längere Abschlagszahlung. ${ }^{142}$ Bei der negativen Einkommenssteuer für Beschäftigte, welche als dauerhafte Lohnsubvention anzusehen ist, verringert sich die Leistung mit höherem Einkommen direkt, da immer nur ein Prozentsatz der Differenz zwischen dem eigenen Einkommen und einem maximalen Satz gezahlt wird. ${ }^{143}$ Das neue RSA soll die Einkommensentzugsrate erheblich mildern und es damit attraktiver machen, in entlohnte Arbeit zurück zu kehren. ${ }^{144}$

Deutschland hat im neuen SGB II seit 2004 schon mehrere Modi ausprobiert und ist jetzt bei einer Mischung von Grundfreibetrag (100€, aber nur zum Ausgleich aller Kos-

136 Zuerst Family Income Supplement 1970, dann Family Credit 1988, das von der negativen Einkommenssteuer für Beschäftigte (mehrere Arten von tax credits) ab 1999 abgelöst wurde; Wikeley, The Law of Social Security (Fußn. 12), S. $382 \mathrm{ff}$.

$1375 £$ (10£ bei Paaren und $20 £$ bei besonderen Personengruppen) je Woche, vgl. CPAG, Welfare benefits and tax credits handbook (Fußn. 86), Chapter 36, S. $847 \mathrm{ff}$.

138 Bei Personen mit Kindern ist der Feibetrag $5.220 £$ im Jahr.

139 R 5425-1 ff. Code du travail.

140 R 5425-2 Code du travail. Manfred Husmann, Leistungen bei Arbeitslosigkeit in Frankreich (Teil II), ZESAR 2008, S. 171, 178.

141 Loi (pour le retour à l'emploi et sur les droits et devoirs des bénéficiaires de minima sociaux) nr. 2006-339 v. 23.3.2006. Vgl. zB für die ASS Code du travail R5425-3.

142 Für die ASS Code du travail Article L5525.

143 S. Fußn. 62 und 63 und die Berechnungen unter: http://www.travail-solidarite.gouv.fr/informations-pratiques/fiches-pratiques/remuneration/primepour-emploi-ppe.html?var_recherche=PPE.

144 S. livre vert vom Februar 2008:

http://www.premierministre.gouv.fr/information/les_dossiers_actualites_19/haut_commissaire_solid arites_actives_920/experimentations_924/livre_vert_sur_rsa_1281 (Fußn. 64). 
ten, da Bruttobeträge angerechnet werden) und einem Freibetrag von $20 \%$ bei Einkommen zwischen 100-800 € und 10\% bei Einkommen zwischen 801-1200 € je Monat angelangt - eine gegenüber dem UK sehr knauserige Lösung. Übergangsregelungen gibt es gar nicht. Wie wenig Problembewusstsein hier bisher bestanden hat, macht das völlige Scheitern des Kindergeldzuschlags (140€ Monat pro Kind) deutlich, der vermeiden sollte, dass allein der Unterhalt für Kinder zum Bezug von „social assistance“ für Erwerbstätige führt. Da zu kompliziert und zu niedrig verfehlte er völlig seine Wirkung und soll attraktiver werden. ${ }^{145}$

Dabei hält Deutschland theoretisch immer noch an einer strikten Trennung von „social assistance" und Lohnsystem fest. Das Gesetz bestimmt, dass der Bedarfssatz in der allgemeinen „social assistance“ so gebildet werden muss, dass bei Haushaltsgemeinschaften von Ehepaaren mit drei Kindern die Regelsätze plus den Leistungen für Unterkunft und Heizung, den Mehrbedarfen für besondere Personengruppen und einem Freibetrag von $30 \%$ des Einkommens unterhalb der erzielten monatlichen durchschnittlichen Nettoarbeitsentgelten unterer Lohn- und Gehaltsgruppen einer alleinverdienenden vollzeitbeschäftigten Person bleiben sollen zuzüglich Kindergeld und Wohngeld ( $\$ 28$ Abs. 4 SGB XII, sog. Abstandsgebot). Für das spezielle „social assistance“-System für Erwerbstätige (SGB II) gilt dieses Gebot nicht ${ }^{146}$ und wäre auch völlig irreal angesichts der oben schon analysierten, wachsenden Funktion der Leistungen des SGB II, niedrige Löhne aufzustocken.

\section{c) Weitere sozialpolitische Aspekte}

Traditionell gibt es neben diesen Lösungen durch Leistungen der „social assistance“ andere Instrumente der Subventionierung von Niedriglöhnen (nach Bedürftigkeit) durch Lohnsubventionen und Kombilohnmodelle, die Absenkung der Beiträge zur Sozialversicherung für Niedrigverdiener ${ }^{147}$ und die - systematisch gebotenen und sachgemäßeren - Freibeträge und gleitende Ausgestaltung des Einkommenssteuertarifs. Sie werden in allen Ländern massiv ausgebaut. ${ }^{148}$

145 BT-Drs. 16/8867 v. 22.4.2008 und 16/ 9792 v. 25.6.2008: Änderung des § 6a BKKG; die Mindestverdienste, ab denen der Zuschlag gezahlt wird, werden abgesenkt (600/900 € Monat Alleinstehende/Paare) und Einkommen oberhalb des ,social assistance“ Satzes (ohne Kinder) wird nur noch zu $50 \%$ angerechnet.

146 Mittelbar wirkt es aber in das SGB II hinein, weil die gesetzliche Regelung, was der Bedarfssatz abdecken soll, gleich ist und allein das SGB XII gesetzliche Regeln für die Ermittlung der Bedarfssätze enthält. Zu dem komplizierten Verhältnis von SGB II und XII in diesem Punkt vgl. LPK SGB II-Münder, § 20 Rdnr. 4 ff., 28 ff.

147 So in Deutschland für Arbeitsverhältnisse unter $400 €$ /Monat und in Frankreich wird bei neu eingestellten Niedrigverdienern der Arbeitgeberanteil an den Sozialabgaben um bis zu 26 Prozentpunkte gesenkt.

148 Sachverständigenrat, Gutachten 2006 (Fußn. 132). 
Alle diese Lösungen führen dazu, das Arbeitseinkommen weit über die „Armutsschwelle“ des allgemeinen Basissatzes der „social assistance“ zu heben und führen zu einer ungeahnten Ausweitung der Bezieher von bedürftigkeitsgeprüften Leistungen. Dazu zwei Beispiele.

Wird in Deutschland das von einigen politischen Parteien favorisierte Modell realisiert, die soziale Einkommensumverteilung in der Krankenversicherung zu beenden und alle Versicherten einen Durchschnittsbeitrag zahlen zu lassen, der bei Niedrigverdienern vom Staat je nach Einkommen subventioniert würde, wäre dies wahrscheinlich die vom Volumen und der Zahl der Betroffenen her größte spezielle Leistung nach Bedürftigkeit. 149

Eine weitere „Rationalitätsfalle“ kann darin liegen, dass bei einer generell gezahlten, auf Unterhaltsansprüche nicht zurückgreifenden ,social assistance“ an Personen über 65, der Anreiz für Personen, die nur ein geringes Arbeitseinkommen haben, für ihr Alter vorzusorgen, nur gering ist. Denn ihre Alterseinkünfte werden unter dem Bedarfssatz der „social assistance“ liegen und damit ganz auf den Bedarfssatz angerechnet. Sie ständen damit nicht besser als jene Personen, die gar nicht für ihr Alter vorgesorgt hätten. Die Lösung wird darin gesehen, die Altersrente auf den Bezug von ,social assistance“ im Alter nicht oder nur teilweise anzurechnen.

In beiden Fällen würden wieder die beiden Wirkungen eintreten, dass die Zahl der Bezieher von „social assistance“ steigt und ihre Leistungen weit über die Armutsgrenze der allgemeinen ,social assistance“ hinausgehen.

\section{d) Zusammenfassung}

Während des Bezugs von „social assistance“ sollen so genannte Armutsfallen dadurch vermieden werden, dass zusätzliches Einkommen aus Arbeit nicht voll, sondern nur zum Teil angerechnet wird, um einen Anreiz zu geben, aus der Erwerbslosigkeit wieder in den Arbeitsmarkt zurück zu kehren und/oder mehr zu verdienen. Im UK werden bei den Leistungen der negativen Einkommenssteuer $63 \%$ des Einkommens über einem großzügigen Freibetrag nicht angerechnet; in Frankreich sind Freibetrag und belassener Betrag erheblich geringer, ungefähr genauso wie die Quote von 10 bzw. $20 \%$ im deutschen SGB II. Alle diese Regelungen führen dazu, dass weit über das Niveau des Existenzminimums hinaus noch social assistance geleistet wird. Damit verliert die Definition von „Bedürftigkeit“, dass eine Person nicht mehr in der Lage ist, aus eigenen Mitteln ihre Existenz zu sichern (oben II. 3. b), an Bedeutung.

149 Je nach Höhe und Ausgestaltung des „Staatszuschusses“ ginge es um ein Volumen zwischen 13-36 Mrd. $€$ und 4-8 Mio. Betroffenen. Vgl. Stefan Greß/Anita Pfaff/Gert G. Wagner, Zwischen Kopfpauschale und Bürgerprämie, Düsseldorf 2005, S. 133 ff.; Sachverständigenrat Jahresgutachten 2004, Ziff. 510 ff.; 2005, Ziff. 561 ff.; BMGS (Rürupkommission), Nachhaltigkeit in der Finanzierung der Sozialen Sicherungssysteme (o.J., 2003), S. 171 ff. und Anhang S. E 3 ff. 


\section{$V$. Besondere rechtliche Strukturen der workfare}

In allen drei Ländern ist die Entwicklung hin zu ausdifferenzierten ,social assistance" Systemen vor allem vorangetrieben und geprägt worden durch die Entwicklung von Sondersystemen für arbeitslose Erwerbsfähige und Erwerbstätige, wie diese Systeme auch - vom Finanzvolumen und der Zahl der Leistungsempfänger her - die wichtigsten „social assistance“ Systeme sind. Ihr Einfluss auf die Entwicklung und Grundstrukturen der „social assistance“ ist z.T. bei den Punkten der Subsidiarität und der Anrechnung von Arbeitseinkommen angesprochen worden. Im Folgenden geht es um die spezifischen Aspekte der workfare und ihre Auswirkungen auf die „social assistance“.

\section{Elemente der „workfare“}

„Workfare“ wird in international vergleichenden Untersuchungen vor allem als ein Merkmal der neueren Entwicklung der „social assistance“ gekennzeichnet. ${ }^{150}$ Bei Beibehaltung der herkömmlichen Merkmale von Fürsorgeleistungen, Bedürftigkeit und Subsidiarität, betont „workfare“ und „Aktivierung“ in der „social assistance“ drei Elemente, ${ }^{151}$ wonach, (1) die Hilfebedürftigen verpflichtet sind (2) eine Arbeit im ersten Arbeitsmarkt aufzunehmen, zumindest sich aber ihr wieder anzunähern, um (3) als Gegenleistung , social assistance“ Leistungen zu erhalten.

Was unterscheidet „workfare“ von der alten „social assistance“ der (bloßen) Existenzsicherung und von anderen speziellen ,social assistance“ Leistungen? In beiden Fällen sind es drei Elemente:

(1) Einmal die Kennzeichnung der Anspruchsberechtigten als zumindest potentielle Arbeitsmarktbürger; ihnen wird allenfalls vorübergehend aus besonderen persönlichen Gründen eine „Auszeit“" vom Arbeitsmarkt zuerkannt (unten 2.). ${ }^{152}$

(2) In Verbindung mit der Absenkung der Leistungshöhe und Leistungsdauer die höheren Anforderungen an die Verpflichtung zur Arbeitssuche und die Zumutbarkeit neuer Arbeit sowie die striktere Durchsetzung dieser Anforderungen (unten 3 und 5). Da-

150 Stark am angelsächsischen Muster orientiert: Jamie Peck, Workfare States, New York 2001, S. 83 ff., 341 ff. Allgemein: Susanne Koch/Gesine Stephan/Ulrich Walwei, Workfare: Möglichkeiten und Grenzen, IAB Discussion Papers, 17/2005.

151 Ivar Lødemel, Workfare, CESifo DICE Report 2/2005, S. 13, 14 („Programmes or schemes that require people to work in return for social assistance benefits"); Ivar Lødemel/Heather Trickey, An Offer you can't Refuse - Workfare in International Perspective, Bristol 2001, S. 7 ff.; Koch/ Stephan/ Walwei, Workfare (Fußn. 150), S. 7.

152 Dies konvergiert mit einer allgemeinen nationalen und europäischen Sozialpolitik, die Beschäftigungspotentiale stärker auszunutzen, Claire Annesley, Lisbon and social Europe: towards a European ,adult worker model“ welfare system, Journal of European Social Policy 2007, S. 195. 
durch wird der Druck auch zu schlechteren Bedingungen in den ersten Arbeitsmarkt zurückzukehren sehr stark.

(3) Schließlich die Verbindung der ,social assistance“ mit neuen Formen der aktiven und aktivierenden Arbeitsmarkpolitik; individuelle Förderleistungen werden integraler Bestandteil dieser Sonder- ,social assistance“ Systeme (unten 4 und 6). Sie sind jedoch stärker oder vollkommen auf eine direkte und schnelle Integration in den ersten Arbeitsmarkt ausgerichtet, langfristige Fördermaßnahmen und gar ein dauerhafter zweiter Arbeitsmarkt werden zurückgefahren.

\section{Die Universalisierung des Erwerbstätigenstatus}

Am deutlichsten ist hier das deutsche System. Das SGB II ${ }^{153}$ erfasst jeden, der über das schulpflichtige Alter hinaus ist und mindestens drei Stunden am Tag arbeiten kann. Personen in Ausbildung oder mit Sorgeverpflichtungen werden erst durch unterschiedliche Ausnahmevorschriften aus dem personellen Geltungsbereich oder nur zeitweise von der Verfügbarkeit für den Arbeitsmarkt freigestellt. Für diese Universalisierung des Erwerbstätigenstatus ist die Ausübung gesellschaftlich notwendiger Sorgearbeit nur noch eine (vorübergehende) Ausnahme. 154

Zwar haben weder Frankreich noch das UK ein einziges System, das einen solchen breiten Anspruch direkt verfolgt. Indirekt liegt ihren ,social assistance“ Systemen aber eine ähnliche Orientierung zu Grunde. In Frankreich ist dies schon allein deshalb der Fall, weil die meisten ,social assistance“ Leistungen in die Sozialversicherung integriert sind und damit an die (frühere) Beitragszahlung in einem Arbeitsverhältnis anknüpfen. Für das selbständige RMI ist die Arbeitsmarktorientierung direkt in die Anspruchsvoraussetzung als „Fernziel“ aufgenommen worden. ${ }^{155}$ Und für das UK wurde die Arbeitsmarktorientierung in den Systemen außerhalb der Arbeitslosenhilfe seit 2000 durch verpflichtende arbeitszentrierte Interviews eingeführt. ${ }^{156}$ Eine wesentliche Lücke wird

153 Personen mit Sorgearbeit für Kinder bis zum 3. Lebensjahr und Pflegebedürftige sind nur teilweise, vorübergehend von der Arbeitspflicht freigestellt $\S 10$ Abs. 1 Nr. 3 und 4 SGB II.

154 Vgl. die Kritik unter Genderaspekten in: Sigrid Leitner u.a. (Hrsg.), Wohlfahrtstaat und Geschlechterverhältnis im Umbruch, Wiesbaden 2004; Ute Gerhard u.a. (Hrsg.), Erwerbstätige Mütter - Ein europäischer Vergleich, München 2003; Silke Bothfeld, Das Stop-and-go in der Politik zur Vereinbarkeit von Familie und Beruf, in: Maria Oppen/Dagmar Simon (Hrsg.), Verharrender Wandel. Institutionen und Geschlechterverhältnisse, Berlin 2004, S. 27 ff.; Lisa Giddings, The Commodification of Lone Mothers' Labor; A Comparison of US and Germany, in: Feminist Economics, July 2004, S. $115 \mathrm{ff}$.

155 Code de l'action sociale et des familles Article L262-1 : Toute personne ... qui s'engage à participer aux actions ou activités définies avec elle, nécessaires à son insertion sociale ou professionnelle, a droit ... à un revenu minimum d'insertion.

156 Zuletzt The Social Security (Incapacity Benefit Work-focused Interviews) Amendment 2005 (No.2) Regulations 2006, (SI 2006 No. 2006/3088) und The Social Security (Work-focused Interviews) Amendment Regulations 2005 (S.I. 2005 No. 2005/2727) sowie $C P A G$, Welfare benefits and tax 
allerdings jetzt geschlossen, als das neue Leistungssystem für Behinderte (ESA) direkt und durchgängig auf die Integration in den Arbeitsmarkt oder arbeitsmarktnahe Aktivitäten ausgerichtet ist. 157

\section{Verpflichtung zur Reintegration in den Arbeitsmarkt}

Alle drei Länder verlangen von den Anspruchsberechtigten die Verfügbarkeit für die Arbeitsvermittlung und als neueres Kriterium, das zuerst im UK statuiert wurde, ${ }^{158}$ die aktive Arbeitsmarktsuche. Bei der Zumutbarkeit einer neuen Arbeit respektiert nur Frankreich ${ }^{159}$ weitgehend die vorherige Qualifikation, das UK sehr begrenzt ${ }^{160}$ - wohl durch die enge Verbindung mit dem Sozialversicherungssystem. Beschränkungen der Verfügbarkeit sind im UK dann zulässig, wenn sie die Chance, eine Arbeit zu finden, beeinträchtigen oder aus besonderen Pflichten zur Pflege von Kindern oder Pflegebedürftigen herrühren. Ähnlich das deutsche SGB II. 161

Beim SGB II, RMI (Frankreich) und ESA (UK) ist die Beschäftigungsbereitschaft nicht Leistungsvoraussetzung, sondern sie wird erst mit der Begründung des Leistungsund Verwaltungsverhältnisses (allmählich) geschaffen und auf die Probe gestellt.

Insgesamt sind die Regelungen in Frankreich und England abgestufter, vor allem weil die Verbindung mit den Voraussetzungen der Versicherungsleistung noch besteht oder die Leistung ausschließlich an ,arbeitsmarktferne“ Gruppen geht.

\section{Vertragliche Strukturen}

International vergleichende Untersuchungen zu den „welfare to work“ Programmen für Sozialhilfeempfänger zeigen, dass alle Länder Eingliederungsvereinbarungen benutzen und oft schon vom Programm her versuchen, den Sozialhilfeempfängern eine wirk-

credits handbook (Fußn. 86), Chapter 38, S. 980, 985 m.w.N. Starke Bedenken in Report by the Social Security Advisory Committee Oct. 2005 Cm 6669.

157 Für die ,work-related component“ wird vorausgesetzt, dass die Empfänger „reasonable steps to manage their condition and to help move towards the workplace" unternehmen, Welfare Reform Bill 2007, Part 1, Clauses 2(3) and 4(5) sowie clauses 11-15. Bonner (Fußn. 38).

158 Eingeführt im UK vgl. A. I. Ogus u.a., The Law of Social Security, 4. Aufl. London 1995, S. 111 ff.; übernommen 1997 ins SGB III $§ 119$ und in den code du travail L 5411-6 und 5421-3 sowie R 5411-9 und 5411-11.

159 ASS: Code du travail L5412-1 : die angebotene Arbeit muss sein „compatible avec leur spécialité ou leur formation, leurs possibilités de mobilité géographique compte tenu de leur situation personnelle et familiale et des aides à la mobilité".

160 Sect 6 Jobseekers Act 1995 und Reg. 6-8 JSA Regulations 1996, SI 1996/207 und CPAG, Welfare benefits and tax credits handbook (Fußn. 86), Chapter 15, S. 340 ff.

$161 \S 10$ und 31 SGB II. 
liche Wahl zwischen mehreren Eingliederungsangeboten zu geben. ${ }^{162}$ Auf der Basis von (freiwilligen) Vorläufern im angelsächsischen Bereich wurde die Eingliederungsvereinbarung zuerst in Frankreich beim RMI 1988 und dann 2001 in der allgemeinen Arbeitslosenversicherung 163 und im UK 1996 für die JSA eingeführt. Deutschland folgte dem sehr vorsichtig als Sonderregelung im Allgemeinen ,social assistance“ Recht 1996,164 sodann 1999 im Arbeitslosenversicherungsrecht (§§ 6, 35 SGB III) und 2004 im SGB II (§ 15). Verträge sind wesentlich, um Motivation zur aktiven Integration zu schaffen, und sie sind möglich, da die Pflichten der Leistungsbezieher nur durch vage Normen geregelt sind und die Förderleistungen im Ermessen der Verwaltung stehen.

Da ohne besondere Sanktionen, ist die Vereinbarung im UK ein rein ,pädagogisches" Instrument, das zusätzliche Motivationen schaffen soll, aber sehr minutiös im Gesetz vorgegeben ist. ${ }^{165}$ In Frankreich ist die Vereinbarung mit Sanktionen bewehrt, aber zugleich stark wie eine ,wirkliche“ Vereinbarung ausgestaltet, die auch die Verwaltung bindet. Es gibt auch entsprechende Urteile. ${ }^{166}$ In Deutschland dagegen überwiegt die „hoheitliche“ Instrumentalisierung der Vereinbarung, sie dient eher dazu, das Sanktionspotential zu erhöhen, was zweifeln lässt, ob sie Motivationen schaffen und Ei-

162 Peter Tergeist /David Grubb, Activation Strategies and the Performance of Employment Services in Germany, the Netherlands and the United Kingdom, OECD Social, Employment and Migration Working Papers, No. 42, 2006, S. 27; Heather Trickey, Comparing workfare programmes - features and implications, in: Ivar Lødemel/Heather Trickey (Fußn. 151), S. 249, 275. Zu entsprechenden Änderungen in Schweden vgl. Nordic Labour Journal 1/2008, S. 5.

163 Mit dem Plan d'aide au retour à l'emploi (PARE) durch die convention du 1er janvier 2001. Zu ihr Dupeyroux, Droit de la sécurité sociale (Fußn. 41), S. 1135 ff. Ob das ab 2006 geltende ,projet personnalisé d'accès à l'emploi (PPAE)“ Code du travail R 5411-14 ff. sowie Convention Anpe-Unédic du 1er juin 2006 (unter: http://info.assedic.fr/unijuridis/index.php?adresse=\%2FLes $\% 20 \mathrm{Textes} \%$ 2Fach06\%2FConventions\%20de\%20partenariat $\% 2$ Fcnv010606 bippae.xml\&chemin $=\% 2 F a c h 06 \% 2$ Fcnv010606bippae.xml\&idPage $=552618 \mathrm{a} 2674 d d 5 f 650 \mathrm{aa9a3d67293c79,19}$. Juni 2008) auch noch als Vertrag gekennzeichnet werden kann, ist zweifelhaft. Er wird im Gesetz und den Konventionen durchgängig nicht als Vertrag, sondern als Plan bezeichnet, der von den Arbeitsmarktbehörden aufgestellt wird. Er hat aber weiterhin kooperative Strukturen („Ce projet est élaboré et actualisé avec le demandeur d'emploi, dans les conditions fixées par les articles R. 311-3-11 et R. 311-3-12 du code du travail, en tenant compte de son degré d'autonomie et de sa distance à l'emploi ; Convention Etat-Anpe-Unédic du 5 mai 2006 relative à la coordination des actions du service public de l'emploi, Art. 4). Für einen Vertrag, wie die Vorläufer PARE und PAP, Borgetto/Lafore, Droit de l'aide et de l'action sociales (Fußn. 7), S. 449 ff. Rdnr. 489; Manfred Husmann, Leistungen bei Arbeitslosigkeit in Frankreich (I), ZESAR 2008, S. 118, 123.

$164 \S 17$ Abs. 2 BSHG i.d.F. des Gesetzes v. 23.7.1996, (BGB1 I 1088): „Wenn zur Überwindung von Hilfebedürftigkeit ein besonderes Zusammenwirken des Hilfsbedürftigen und des Trägers der Sozialhilfe erforderlich ist, soll hierüber in geeigneten Fällen eine schriftliche Vereinbarung abgeschlossen werden".

165 Sect 7 und 8 Jobseeker's Act plus Reg 18 ff. und 31 ff. Jobseeker's Allowance Regulations 1996 SI 1996/207.

166 Code de l'action sociale et des familles article L. 262-37 Abs. 3 „Le contrat est librement conclu par les parties et repose sur des engagements réciproques de leur part“. TGI de Marseille 15.4.2004, Droit Social 2004, 545; Cour D'Appel D'Aix-En-Provence, Droit Social 2004, 964. Christophe Willmann, Le non-respect des engagements pris aut titre du PARE, RDSS 2004, S. 701. 
geninitiative stärken kann. Entsprechend der unterschiedlichen Ausgestaltung wundert es nicht, dass die „Vereinbarung“ als solche im UK rechtsdogmatisch so gut wie nicht analysiert worden ist, während in Frankreich ${ }^{167}$ die Diskussion um Rechtsnatur und Verbindlichkeit sehr intensiv geführt wurde. In Deutschland ${ }^{168}$ geht es angesichts der stark hoheitlichen Ausrichtung eher darum, die Rechtnatur und den Unterschied zum Verwaltungsakt zu klären.

\section{Sanktionen}

Alle drei Länder verwenden die üblichen Sanktionen bei Verletzung der Pflichten zur Arbeitssuche. Standardmäßig werden bei Arbeitslosen vier Pflichtverletzungen mit Sanktionen belegt: 169

Traditionell:

- Das Arbeitsverhältnis wurde ohne wichtigen Grund selbst gekündigt oder durch vertragswidriges Verhalten wurde Anlass für eine Arbeitgeberkündigung gegeben;

- zumutbare Arbeit wird ohne wichtigen Grund abgelehnt.

Neu seit den 70/80 Jahren:

- Eigene Aktivitäten der Arbeitssuche werden nicht nachgewiesen und angebotene Fördermaßnahmen werden nicht aufgenommen oder abgebrochen.

Nur Deutschland hat, wie gesagt, zusätzlich spezielle Sanktionen bei Verletzung der Verpflichtungen aus der Eingliederungsvereinbarung und das UK ${ }^{170}$ kennt den generellen Tatbestand des unkooperativen Verhaltens gegenüber der Arbeitsverwaltung. Im UK und in Frankreich verhängt nicht der betreuende Arbeitsvermittler, sondern andere Instanzen/Beamte die Sanktionen, was eher gewährleistet, die unmittelbare Betreuung frei von hoheitlichen Elementen zu halten. Die Verhängung der Sanktionen steht im UK und Frankreich im Ermessen der Verwaltung, während sie in Deutschland zwingend zu ver-

167 Borgetto/Lafore, Droit de l'aide et de l'action sociales (Fußn. 7), S. 478 ff. Rdnr. 525 ff. und S. 518 ff. Rdnr. 560 ff. m.w.N. Die Eingliederungsrechte können durch den Vertrag nicht geschmälert werden: Commissaire du gouvernement in Conseil d'État 23 avril 2007, Département des Deux Sèvres, n. 282963 RDSS 2007, S. 714, 719: droit à l'insertion et devoir d'insertion.

168 Umfassend: Uwe-Dietmar Berlit, Eingliederungsvereinbarung nach dem SGB II - Rechtsrahmen und Rechtsschutz, Sozialrecht aktuell 2006, 41 und Wolfgang Spellbrink, Eingliederungsvereinbarung nach SGB II und Leistungsabsprache nach dem SGB XII aus Sicht der Sozialgerichtsbarkeit, Sozialrecht aktuell 2006, S. 52.

169 UK: Sect. 19 subsect. 5 Nr. a und subsect. 6 sowie sect. 20A subsect. 2 Nr. a und d-g Jobseekers Act 1995; Reg 69 ff. Jobseeker's Allowance Regulations 1996 SI 1996/207. Frankreich: code du travail L 5412-1 und R 5412-1 ff. sowie Article L5426-2 und Article R5426-3. Deutschland: § 31 SGB II.

170 UK: Sect 19 subsect. 5 Nr. a Jobseekers Act 1995 („,has, without good cause, refused or failed to carry out any jobseeker's direction which was reasonable“), Reg 69 ff. Jobseeker's Allowance Regulations 1996 SI 1996/207. 
hängen sind, was bei einem System mit extrem unterschiedlichen Leistungsberechtigten zu wenig differenziert erscheint.

Auch die Art der Sanktion ist die gleiche: Eine zeitweilige Suspendierung (UK) oder Minderung (Deutschland und Frankreich) der Zahlung. In Deutschland und Frankreich ist die Zeitdauer der Suspendierung/Kürzung für die einzelnen Fälle jeweils genau vorgeschrieben (1/3 für 3 Monate bzw. 20-100 \% für 2-6 Monate), während im UK meist ein Spielraum besteht (1-26 Wochen).

Die Praxis der Sanktionierung ist schwer vergleichbar. Soweit dies versucht wurde, unterscheiden sich die drei Länder zwar stark in den verschiedenen Kategorien der Sanktionierung, nicht aber in der Gesamtzahl. ${ }^{171}$ Wegen seiner stark kooperativen Ausrichtung ist es plausibel, wenn für Frankreich ${ }^{172}$ eine besonders geringe Zahl an Sanktionen festgestellt wird.

\section{Einbezug in die Förderleistungen}

Das letzte Element der workfare, der bessere Einbezug der erwerbsfähigen (Dauer-) Arbeitslosen in die Förderleistungen zur Reintegration in den Arbeitsmarkt, ist explizites Ziel in allen drei Ländern und folgt auch ähnlichen Mustern. Diese Komponente ist eng mit der Betonung der Pflichten der Leistungsbezieher zur Reintegration und den Sanktionen verbunden.

Die Förderleistungen sind in allen drei Ländern Ermessensleistungen, nur in Deutschland sind sie intensiv gesetzlich normiert. ${ }^{173}$ Die Muster der Einbeziehung in die Förderleistungen gleichen sich im ersten Schritt. Vor bzw. zu Beginn der Leistungsgewährung steht eine umfassende Bestandaufnahme der Fähigkeiten und Bedarfe der arbeitslosen Leistungsberechtigten/Profiling. ${ }^{174}$ Wirklich zwingend ist sie aber in keinem der drei Länder ${ }^{175}$ vorgeschrieben.

Ansonsten sind die Programme im Ansatz sehr unterschiedlich, auch wenn durch den regen Transfer von Erfahrungen in allen Ländern ähnliche Instrumente eingesetzt werden.

171 David Gray, National versus Regional Financing and Management of Unemployment and Related Benefits, OECD Social, Employment and Migration Working Papers, No. 14, 2003, S. 12; Tergeist,/Grubb, Activation Strategies and the Performance of Employment Services (Fußn. 162), S. $27 \mathrm{ff}$.

172 Laurent Fraise, Executive Summary France, in: Ivar Lødemel (ed.), Workfare in Six European Nations, Fafo Paper 2002:24, Oslo 2002, S. 13 ff.

173 Über § 16 Abs. 1 SGB II finden die sehr minutiösen Regelungen des SGB III (Förderung in der Arbeitslosenversicherung) Anwendung.

$174 \mathrm{Zu}$ ihm und seiner Bedeutung Tergeist/Grubb, Activation Strategies and the Performance of Employment Services (Fußn. 162), S. 22 ff.

175 Außer bei der ESA im UK vgl. Bonner, Employment and Support Allowance (Fußn. 38). 
Ein wichtiges Instrument, das die Autonomie der Leistungsberechtigten erhöht, sind die Gutscheine für die Arbeitsvermittlung und Qualifizierungsmaßnahmen in Deutschland. ${ }^{176} \mathrm{Neu}$ ist ebenfalls die Übertragung der gesamten Arbeitsmarktintegration in Deutschland ${ }^{177}$ und im UK ${ }^{178}$ an private Dienstleister, die nach Erfolg und/oder Fall bezahlt werden.

\section{Die Ausweitung: Von der workfare zur Inklusion}

Nach den langen Erfahrungen mit workfare Politiken im UK ist (fast) allgemein akzeptiert, dass sie gut geeignet sind für Personen mit engen Verbindungen zum Arbeitsleben und/oder mit ausmachbaren, spezifischen sozialen Problemen, weniger oder nicht geeignet für Personen mit mehrfachen Problemen und langer Abwesenheit vom Arbeitsmarkt. ${ }^{179}$ Die Folge aus dieser Erkenntnis ist zweierlei: Es ist ein umfassender Hilfeansatz notwendig, der weniger auf Geld, als vielmehr auf soziale Dienstleistungen abstellt, und der zweitens in der Bemessung der Bedarfe und der ihnen entsprechenden Leistungen (vorerst) nicht die Beschäftigungsfähigkeit, sondern die allgemeine soziale Teilhabe (Inklusion) stärkt. Die Politik der Sozialen Inklusion ist in Frankreich sehr alt und speist sich dort aus dem Ideal der republikanischen Gleichheit. ${ }^{180}$ Sie ist mittlerweile einer der wichtigsten Ansätze der Europäischen Sozialpolitik. ${ }^{181}$ Explizit verwirklichen diesen Ansatz aber nur die Systeme für Nicht-Erwerbsfähige in allen drei

$176 \S \S 77$ Abs. 3 und 417 Abs. 1, 421g SGB III. Mit Gesetz v. 11.04.2008 (BGB1 I 681) gibt es jetzt auch einen „Eingliederungsgutschein“ für ältere Arbeitslose $§ 223$; diese Instrumente gelten auch für das SGB II (§ 16 Abs. 1).

$177 \S 421$ i SGB III, der gem. $\S 16$ Abs. 1 auch für das SGB II gilt.

178 So schon die Job Broker im Programm für die Integration Behinderter vgl. Bruce Stafford et al., New Deal for Disabled People: Third Synthesis report - key findings from the evaluation, Dept. For Work and Pensions, Research Report No. 430, Leeds 2007, S. 59 ff., und allg. die Emploment Zones, zu ihnen Oliver Bruttel, „Employment Zones“ als innovatives Modell der Arbeitsvermittlung, BArbBl 6-2005, S. 18 ff. und Tergeist/Grubb, Activation Strategies and the Performance of Employment Services (Fußn. 162), S. 18 ff., 41 ff. sowie Rita Griffiths/Stuart Durkin, Synthesising the evidence on Employment Zones, Department for Work and Pensions, Research Report No 449, Leeds 2007.

179 Dean, Re-Conceptualising Welfare to Work for People with Multiple Problems and Needs, Journal of Social Policy (2003) 32, S. 441.

180 Jean-Michel Belorgey/Jean-Jacques Dupeyroux/Jean-Marie Albertini, L'Exclusion sociale, Paris 1974; Barbier/Théret, in: Neil Gilbert/Rebecca A. Van Voorhis (Hrsg.), Activating the Unemployed (Fußn. 18), S. 158 ff.; Bernard Enjolras et al., Between subsidiarity and social assistance - the French republican route to activation, in: Lødemel/Trickey (Fußn. 151), S. 41 ff.

181 Vgl. z. B. Beschluss des Rates v. 22.7.2003 über die Leitlinien für beschäftigungspolitische Maßnahmen der Mitgliedstaaten, AblEU 5.8.2003, L197 S. 13 ff. unter „Stärkung des sozialen Zusammenhalts und der sozialen Eingliederung" sowie European Trade Union Institute, Six Years of the European Employment Strategy, Brüssel 2004. 
Staaten: RMI, SGB XII und das neue ESA; das breite SGB II enthält allerdings auch einige Elemente.

\section{Allgemeine sozialrechtliche und sozialpolitische Einordnung des Wan- dels}

\section{Zusammenfassung}

a) Unter Beibehaltung traditioneller Strukturen haben sich alle drei Länder zu Zwei-/ Mehrsäulenmodellen der ,social assistance“ gewandelt. Im UK hat die Sozialversicherung ihre prägende Bedeutung verloren und ist voll mit der „social assistance“ zu einheitlichen Leistungssystemen verbunden.

b) Spezielle Systeme der „social assistance“ erfüllen neben der Existenzsicherung immer weitere Funktionen und werden dementsprechend von zusätzlichen Voraussetzungen abhängig gemacht. So sollen die ,social assistance“ Leistungen an arbeitslose Erwerbsfähige die Integration in den ersten Arbeitsmarkt fördern, verlangen also als Voraussetzung auch die Integrationsfähigkeit und Integrationsbereitschaft der Leistungsberechtigten.

c) Die Einführung von Systemen spezieller „,social assistance“, insbesondere solcher für Erwerbsfähige, hat wesentliche Strukturmerkmale des „social assistance“ verändert:

(1) Migranten ohne gesicherten Aufenthalts- und Arbeitsmarktstatus erhalten eine niedrigere existenzsichernde Leistung, als die allgemeine ,social assistance“; es gibt einen doppelten Standard des „Existenzminimums“.

(2) Die Abgrenzung zwischen Erwerbsfähigen und Nichterwerbsfähigen bestimmt zentral den Status eines Empfängers von „social assistance“.

(3) Da für die „social assistance“ Leistungen an arbeitslose Erwerbsfähige der selbständige Arbeitsmarktbürger, der sich selbst ernährt, Leitbild ist, wird er auch zunehmend weniger auf Unterhaltsansprüche verwiesen; die Subsidiarität der ,social assistance“ wird eingeschränkt. Dies gilt auch für andere spezielle Systeme der „,social assistance", da diese ja auch sie davon ausgehen, dass die Hilfebedürftigkeit legitim und der Rückgriff auf Verwandte deshalb weniger angebracht ist.

(4) Um „Armutsfallen“ zu vermeiden, wird zusätzliches Einkommen nicht voll entzogen und „social assistance“ weit über die Grenze der Sicherung des Existenzminimums hinaus geleistet. „Social assistance“ dient dazu, zu niedrige Marktlöhne auszugleichen.

d) Alle Länder praktizieren ,workfare“/Aktivierungspolitik mit folgenden Elementen:

(1) Möglichst viele Empfänger werden zu Arbeitsfähigen mit den entsprechenden Integrationspflichten (Universalisierung des Arbeitsmarktstatus). 
(2) Die Leistung ist eng mit der Bereitschaft zur Integration sowie Fördern und Fordern verbunden.

(3) für alle Leistungsempfänger werden Förderleistungen zur Reintegration in den Arbeitsmarkt zur Verfügung gestellt.

e) Unterschiede in der rechtlichen Struktur der „workfare“ liegen in der Technik der Verbindung von Leistungen und der Integrationsbereitschaft und der Intensität, mit der Zwang und der Anreiz zur freiwilligen Kooperation in „Verträgen“ mit der Verwaltung eingesetzt werden.

f) Alle drei Länder setzten das Instrument des Eingliederungsvertrags ein. Er hat die Funktion, das Leistungsverhältnis zu konkretisieren und die Kooperation zu verbessern. Die Eingliederungsvereinbarung ist in Deutschland stark hoheitlich geprägt; im UK etwas, in Frankreich stärker kooperativ und mit breitem Ermessen der Arbeitsvermittler. Als Vertrag im engeren Sinne ist sie aber nur in Frankreich anerkannt.

g) Alle drei Länder gruppieren und hierarchisieren den Einsatz von Zwang und die Gewährung von Statusschutz in der „,social assistance“ für Erwerbslose: (1) die „armen“ Erwerbstätigen, die ohne weitere Pflichten ihre Leistungen erhalten; (2) jene arbeitslosen bedürftigen Erwerbsfähigen, die aus sozial akzeptierten Gründen nicht erwerbstätig sein müssen und zudem besondere Bedarfe haben (Alleinerziehende; Pflegepersonen); (3) die gerade aus dem Arbeitsmarkt ausgeschiedenen, noch nahe der Arbeitslosenversicherung versorgten Erwerbslosen, deren früherer beruflicher Status noch vorübergehend geschützt wird, an die aber schon hohe Anforderungen gestellt werden (ASS Frankreich, teilweise JSA UK); (4) die allgemeinen bedürftigen Erwerbslosen, an die hohe Anforderungen gestellt und die über Kooperation wie Zwang aktiviert werden sollen; (5) die (noch) nicht arbeitsmarktfähigen (erwerbsgeminderten/behinderten) Arbeitslosen, bei denen überwiegend mit Anreizen gearbeitet wird (Frankreich RMI; UK ESA; Deutschland SGB XII). Nur Deutschland versucht, mit einem System (SGB II) gleich vier „Stufen“ zu überbrücken.

h) In allen drei Ländern besteht die Tendenz, die Administration der „social assistance" für Erwerbsfähige zu regionalisieren, in der Finanzierung und strategischen Kontrolle bleiben in England und Frankreich jedoch starke zentralisierende Elemente.

\section{Wandel im Gerechtigkeitsparadigma}

Sozialrecht und Sozialpolitik als Ganzes verwirklichen immer mehrere Gerechtigkeitskonzepte. ${ }^{182}$ Die bedürftigkeitsgeprüfte, allgemeine existenzsichernde ,social assistance“" hat ihre Wurzeln in der Zeit vor der Moderne, in der christlichen Nächstenliebe und dem Gerechtigkeitskonzept einer Befriedigung menschlicher Bedürfnisse von

182 Vgl. Hans F. Zacher, Sozialrecht und Gerechtigkeit, in: ders. (Hrsg.), Abhandlungen zum Sozialrecht, München 1993, S. 308 ff., 319 ff. Zur Pluralität: David Miller, Grundsätze sozialer Gerechtigkeit, Frankfurt a.M. 2008. 
und nach Bedarf. ${ }^{183}$ Heute sind sie säkularisiert zum Hilfe- und Bedarfsprinzip auf der Basis der Gemeinschaft und Solidarität aller Staatsbürger oder kleinerer Gemeinschaften und der Basis der Humanität, der Achtung der Menschenwürde.

Schon wenn ich die Einzelperson ernst nehme und respektiere, muss ich den „Bedarf" und die „Hilfebedürftigkeit“" genauer analysieren, differenzieren und typisieren. Und da in der modernen individualisierten Erwerbsgesellschaft Hilfe immer auch an die individuelle Verantwortlichkeit anknüpft und als Hilfe zur Selbsthilfe verstanden wird, ist die Differenzierung nach Bedarfsgruppen einer modernen „social assistance“ inhärent. Sie schafft auch eine präzisere Legitimation für die jeweilige Leistung.

Damit gibt es ein „social assistance“ System, das weitgehend voraussetzungslos ist und nur „Hilfebedürftigkeit“ verlangt, nur für jene, die sich kaum noch selbst helfen können. Dies ist der Fall in allen drei Ländern mit dem SGB XII, RMI und Income Support.

Die Betonung der workfare versucht, in bedürftigkeitsgeprüfte Leistungen Elemente der Gerechtigkeit einer Marktgesellschaft einzubringen, der Verteilung nach Leistung und über die Gegenseitigkeit des Tausches. Sicherlich nicht im Sinne einer strikten Äquivalenz, wohl aber der Reziprozität. 184 Dies ist kein Gegensatz zum Hilfe- und Bedarfsprinzip. Entscheidend ist vielmehr, inwieweit Elemente des Vertragsmodells, der Gegenseitigkeit und des Respekts vor dem anderen, auch ernst genommen werden. Dazu gehören vor allem drei Elemente der ,workfare“:

- die intensive Bedarfs- und Fähigkeitsanalyse vor jeder Leistungsgewährung und die Differenzierung der Hilfen und Sanktionen nach diesen Potentialen;

- ein „Vertragsregime“, das seinen Namen wirklich verdient und den Hilfebedürftigen respektiert, muss „Parität“ schaffen und nicht ein verkapptes hoheitliches Instrument der Lenkung und des Zwangs sein;

- umstritten ist nicht, dass beides zu realisieren ist, Fördern und Fordern. Vielmehr ist problematisch zum einen das jeweilige Gewicht der beiden Elemente, zum anderen das Ungleichgewicht, dass die Pflichten der Arbeitslosen klar geregelt und die Sanktionen scharf sind, dass aber nur nach Kassenlage gefördert wird, und schließlich, dass ein starkes Fordern und ein nicht hinreichendes Fördern gerade jene unverhältnismäßig negativ treffen wird, die sowieso auf dem Arbeitsmarkt benachteiligt sind und keine gleichen und fairen Startchancen hatten und haben. 185

183 Miller, Grundsätze sozialer Gerechtigkeit (Fußn. 182), S. 254 ff.

$184 \mathrm{Zu}$ ihr Carsten Ullrich, Reziprozität und die soziale Akzeptanz des „Sozialversicherungsstaates“, Soziale Welt (50), 1999, S. 7, ausführlicher ders., Solidarität im Sozialversicherungsstaat, Die Akzeptanz des Solidarprinzips in der gesetzlichen Krankenkasse, Frankfurt a.M. 2000.

185 So unter Gerechtigkeitsgesichtspunkten: Stuart White, A progressive politics of responsibility, Public policy research 12 (2005), S. 7 ff. Zur Empirie über die ungleichen Wirkungen der workfare und die hohen Förderbedarfe der benachteiligten Gruppen Regina Konle-Seidl, Hilfereformen und Aktivierungsstrategien im internationalen Vergleich, IAB-Forschungsbericht 7/2008, Nürnberg 2008, S. $85 / 86$. 
Die Entwicklung der ,social assistance“ in Deutschland, Frankreich und im Vereinigten Königreich

Insoweit reduzieren sich die normativen Anforderungen an die workfare auf Prinzipien, die eher Tugenden, aber auch Gerechtigkeitsprinzipien sind: Die der Ausgewogenheit und der Fairness, die zwar alt, aber schwer zu realisieren sind. 


\title{
Soziale Hilfe und soziale Förderung in Frankreich im Rahmen der ,action sociale“
}

\author{
Gerhard Igl
}

I. Verständigung über Terminologisches

II. Soziale Hilfe und soziale Förderung im Code de l'action sociale et des familles

III. Zusammenfassung: Erklärungsversuche für die unterschiedliche Gestaltung der sozialen Hilfe und sozialen Förderung in Frankreich und in Deutschland

\section{Verständigung über Terminologisches}

Die erste Hürde, die sich für den Rechtsvergleicher auftut, ist die terminologische Hürde: Wie soll man den Titel des hier zu behandelnden Themenblockes „Das Leistungsverhältnis in Förderungs- und Hilfesystemen“ ins Französische übersetzen? Man könnte es versuchen mit „Le rapport de prestation dans les systèmes de promotion et d'aide“. Es ist aber ziemlich fraglich, ob diese Übersetzung Assoziationen sozialrechtssystematischer Art in Hinblick auf das französische Sozialrecht erweckt. Hinter der terminologischen Hürde verbirgt sich in der Regel nicht nur ein semantisches Benennungsproblem, sondern meist eine inhaltliche, hier eine systemische Frage. In den Vorfragen zu den Methoden des Sozialrechtsvergleichs hat Hans F. Zacher vor mehr als 30 Jahren den Systembezug typischer sozialer Lagen artikuliert. ${ }^{1}$ Im Sozialrechtsvergleich mit Frankreich ist der Systemvergleich mit Förderungs- und Hilfesystemen und deren Leistungen nicht unproblematisch, aber auch nicht ungangbar.

Karl-Jürgen Bieback spricht in seinem Beitrag² von der Sozialhilfe als eigenständigem Zweig der sozialen Sicherheit. Und schon hat der Rechtsvergleicher ein Problem, der sich auf die Suche nach einem französischen Pendant zum deutschen Sozialhilferecht, auf die Suche macht zu einem Gesetzbuch, in dem die Übersetzung des deutschen

1 Zacher, Hans F., Vorfragen zu den Methoden der Sozialrechtsvergleichung, in: ders. (Hrsg.), Methodische Probleme des Sozialrechtsvergleichs, Berlin 1977, S. 21 ff. (48 ff.).

2 Bieback, Hans-Jürgen, Die Entwicklung der ,social assistance“ in Deutschland, Frankreich und im Vereinigten Königreich, in diesem Band, S. 217 ff. 